\title{
Heat transfer coefficients during the condensation of low mass fluxes in smooth horizontal tubes
}

\author{
J.P. Meyer ${ }^{1}$, D.R.E. Ewim
}

17 August 2017

Department of Mechanical and Aeronautical Engineering, University of Pretoria, Pretoria, Private Bag X20, Hatfield 0028, South Africa.

\section{Highlights}

- Measured condensing heat transfer coefficients at low mass fluxes in a smooth horizontal tube at different temperature differences.

- The experiments were also conducted at different wall and saturation temperature differences varying between 3 and $10^{\circ} \mathrm{C}$.

- Results showed that the flow patterns during condensation were predominantly stratified and stratified wavy.

- It was also found that the heat transfer coefficients were dependent on the temperature difference between the temperature of the wall on which condensation occurs and the temperature of the condensing refrigerant.

- An amendment was suggested in a stratified heat transfer coefficient term from literature. It has been found that, with this amendment, the heat transfer coefficients of low mass fluxes could be estimated with errors of $\pm 5 \%$.

\footnotetext{
${ }^{1}$ Corresponding author E-mail address: josua.meyer@up.ac.za (J.P. Meyer) Phone: +27 (0)12 4203104
} 


\section{ABSTRACT}

Until now, no study that systematically investigates the influence of low mass fluxes and temperature differences on condensation heat transfer coefficients has been conducted. Thus, the purpose of this study was to measure condensing heat transfer coefficients at low mass fluxes in a smooth horizontal tube at different temperature differences. Experiments were conducted by condensing R134a in a smooth horizontal tube with an internal diameter of $8.38 \mathrm{~mm}$ and a length of $1.5 \mathrm{~m}$. Experiments were conducted at a saturation temperature of $40^{\circ} \mathrm{C}$ at different qualities, and at low refrigerant mass fluxes that ranged from $50-200 \mathrm{~kg} / \mathrm{m}^{2} \mathrm{~s}$. The experiments were also conducted at different wall and saturation temperature differences varying between $3-10^{\circ} \mathrm{C}$. The flow patterns were recorded with a high speed video camera at the inlet and outlet of the test section through sight glasses. An uncertainty analysis showed that the maximum uncertainty of the heat transfer coefficients and vapour qualities of the data presented in this study were $12 \%$ and 5\%, respectively. Results showed that the flow patterns during condensation were predominantly stratified and stratified wavy. It was also found that the heat transfer coefficients were dependent on the temperature difference between the temperature of the wall on which condensation occurs and the temperature of the condensing refrigerant. Furthermore, it was found that the heat transfer coefficient decreased with an increase in this temperature difference. When comparing the results of this study at low mass fluxes to the literature, it was found that the absolute mean deviation varied up to $38 \%$. An amendment was suggested in a stratified heat transfer coefficient term from literature. It has been found that, with this amendment, the heat transfer coefficients of low mass fluxes could be estimated with errors of $\pm 5 \%$.

Keywords: condensation; low mass fluxes; temperature difference; heat transfer coefficient; smooth tube; flow pattern; stratified; stratified wavy, 


\section{Nomenclature}

\begin{tabular}{|c|c|}
\hline$A$ & area \\
\hline$C_{p}$ & specific heat \\
\hline$d$ & diameter \\
\hline$E B$ & energy balance \\
\hline$f$ & function \\
\hline$g$ & gravitational acceleration \\
\hline$G$ & mass flux \\
\hline$h$ & enthalpy \\
\hline$J_{V}$ & dimensionless gas velocity \\
\hline$J_{V}^{T}$ & transition dimensionless gas velocity \\
\hline$k$ & thermal conductivity \\
\hline$L$ & length of test section \\
\hline$\dot{m}$ & mass flow rate \\
\hline $\operatorname{Pr}$ & Prandtl number \\
\hline$\dot{Q}$ & heat transfer rate \\
\hline$R$ & thermal resistance \\
\hline $\operatorname{Re}$ & Reynolds number \\
\hline$T$ & temperature \\
\hline$x$ & vapour quality \\
\hline$z$ & axial direction \\
\hline
\end{tabular}

\section{Greek symbols}

$\begin{array}{ll}\alpha & \text { heat transfer coefficient } \\ \mu & \text { dynamic viscosity } \\ \rho & \text { density }\end{array}$




\section{Subscripts}

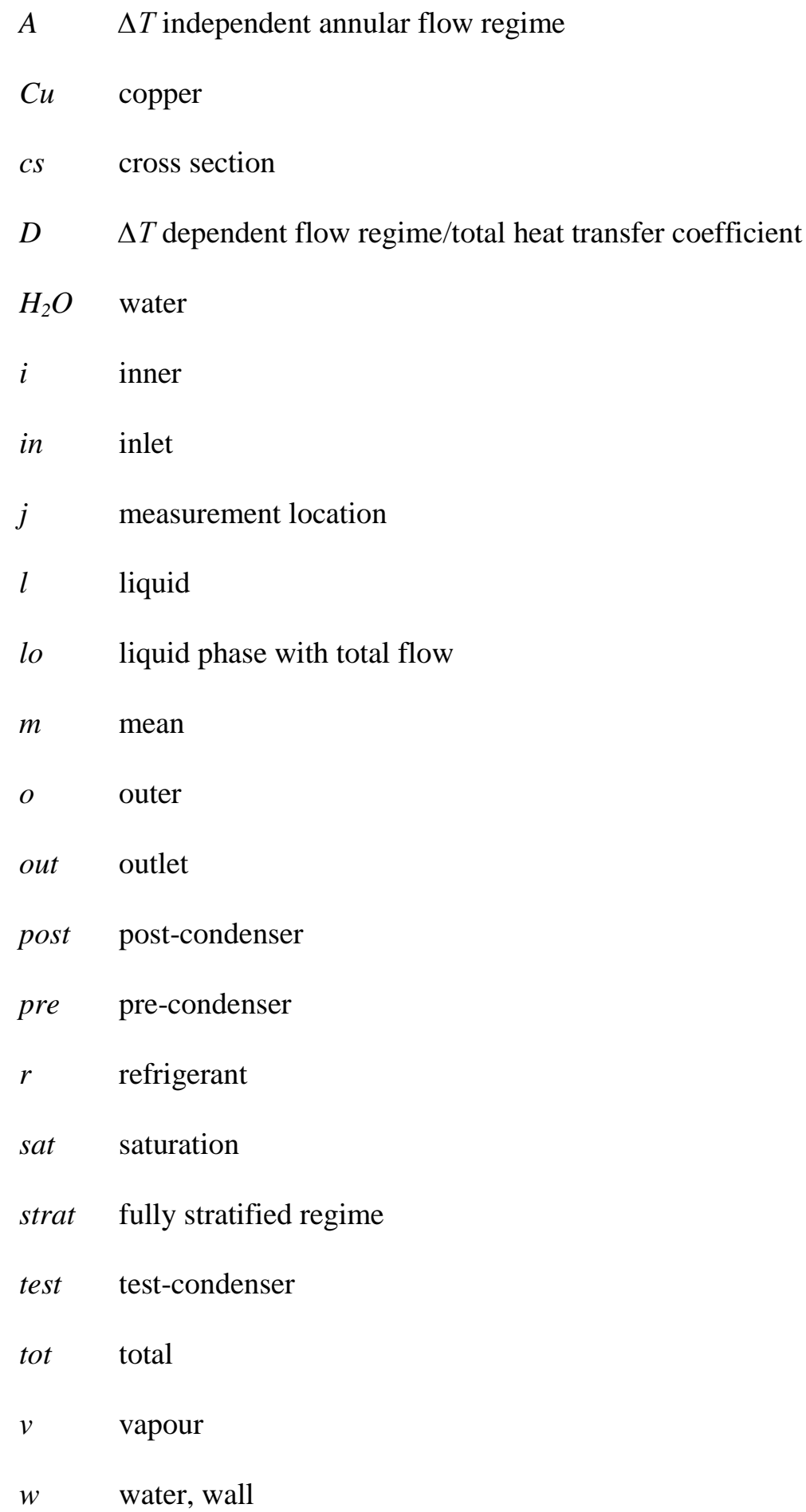




\section{Introduction}

Proper prediction of heat transfer coefficients is key to the design and optimisation of condensers. Therefore, several studies have been carried out on condensation heat transfer inside smooth horizontal tubes. Reviews of these works in both macro- and micro-channels are available in [1-44]. The state of the art is that several reliable correlations [25, 41, 45-48] were developed based on flow regimes, and for that reason, new flow regime maps [30, 49] were developed. However, in general, most of the above works were conducted at mass fluxes varying from approximately 200$1000 \mathrm{~kg} / \mathrm{m}^{2} \mathrm{~s}$.

Some of these and other studies $[18-20,26,28,34,50,51]$ found that the temperature difference between the wall on which condensation occurs and the saturation temperature (hereafter referred to in this paper as the "temperature difference") had a negligible influence on the heat transfer coefficients. The results were, in general, dependent on mass flux and quality. The results generated at low mass fluxes were generally secondary data and not part of the foci of previous works. Furthermore, Thome [52] pointed out that, as opposed to external condensation, the heat transfer coefficients during in-tube condensation were independent of temperature difference, except at low mass fluxes.

Aprea et al. [37] measured the local heat transfer coefficients during the condensation of R22 and $\mathrm{R} 407 \mathrm{C}$ in a $20 \mathrm{~mm}$ diameter, horizontal smooth tube at saturation temperatures varying between $37^{\circ} \mathrm{C}$ and $40^{\circ} \mathrm{C}$. They conducted experiments at mass fluxes of $45-120 \mathrm{~kg} / \mathrm{m}^{2} \mathrm{~s}$. They found that their experimental points at low mass fluxes fell into the stratified wavy flow regime. They compared the results of their experiments with some correlations [53-56] and found that the correlation of Dobson and Chato [57] predicted their results to within an accuracy of $13 \%$. However, they did not study the effect of temperature difference on the heat transfer coefficients. 
Suliman et al. [30] performed heat transfer experiments at mass fluxes ranging between $75-300$ $\mathrm{kg} / \mathrm{m}^{2} \mathrm{~s}$ during the in-tube condensation of R134a in a smooth horizontal tube with an inner diameter of $8.38 \mathrm{~mm}$ at a nominal saturation temperature of $40^{\circ} \mathrm{C}$. They found that at low mass fluxes, the heat transfer coefficients were dependent on temperature differences. They also presented an improved flow pattern map, which was a slight modification of the map proposed by El-Hajal et al. [49]. However, they only acquired two data points for the lowest mass flux of $75 \mathrm{~kg} / \mathrm{m}^{2} \mathrm{~s}$.

Arslan and Eskin [23] experimentally measured the heat transfer coefficients during the in-tube condensation of R134a in a vertical smooth tube. This study is one of a few that addressed the effect of temperatute difference, although the flow was in a vertical downward tube. They considered only downward flows within a low mass flux range of $20-75 \mathrm{~kg} / \mathrm{m}^{2} \mathrm{~s}$. Their condensation experiments were conducted at relatively low saturation temperatures ranging from $20-30^{\circ} \mathrm{C}$. They concluded that the heat transfer coefficients decreased with an increase in saturation temperature, and that, at such low mass fluxes, the heat transfer coefficients were dependent on the temperature difference. They also found that their experimental heat transfer coefficients increased as mass flux increased. Their findings were in agreement with those of Meyer et al. [20] and several others. They found that the correlation of Akers et al. [58] best predicted their results with a deviation of 23\%; however, they did not present data as a function of vapour quality. Furthermore, they did not consider a horizontal tube orientation.

Lee and Son [24] presented the results of their experiments during the condensation of R134a, R290a, $\mathrm{R} 600 \mathrm{a}$, and R22 in different smooth horizontal tubes at a saturation temperature of $40^{\circ} \mathrm{C}$. Their lowest mass flux was $35.5 \mathrm{~kg} / \mathrm{m}^{2} \mathrm{~s}$, while their maximum was $210.4 \mathrm{~kg} / \mathrm{m}^{2} \mathrm{~s}$. Their work was more of a comparative study between the heat transfer characteristics of the different refrigerants in the search for replacement refrigerants. They did not study the effect of the temperature difference on the heat transfer coefficients. However, just as other researchers, they found that the heat transfer coefficients increased with increasing quality and mass flux. Comparing the results of their experiments with 
correlations, they found that the Haraguchi et al. [59] correlation was the most reliable for predicting the range of their experimental data.

It can therefore be concluded from previous studies that insufficient work has been conducted at low mass fluxes, specifically to determine the heat transfer coefficients and capture the flow regimes as functions of temperature differences and vapour quality. Therefore, it was the purpose of this study to experimentally determine the heat transfer coefficients in a smooth horizontal tube at low mass fluxes and different quality values. During experimentation, the flow regimes were also captured at the inlet and outlet of the test section, and these results are also presented here. The experimental data was also compared to literature, and existing literature was modified to generate an equation that could be used to more accurately estimate the heat transfer coefficients at low mass fluxes.

\section{Experimental apparatus and procedure}

The test bench used for this investigation is well established and has previously been used for condensation studies $[6,18,20,29,30,35,51,60-64]$. Slight modifications were, however, made to accommodate the low mass flux requirements of this project. The experimental test rig (Figure 1) consisted of a vapour compression refrigerant cycle (red lines in figure) and several water cycles (blue lines in figure).

The vapour compression cycle consisted of the test section line and the bypass line, which are both high pressure lines, and a low pressure line through which the R134a was pumped using a hermetic scroll compressor with a nominal capacity of $10 \mathrm{~kW}$. Each of the lines had electronic expansion valves which controlled the mass flow rate of the refrigerant. The expansion valve in the test section line that was used in all previous work was replaced with an electronic expansion valve with a smaller valve port. 


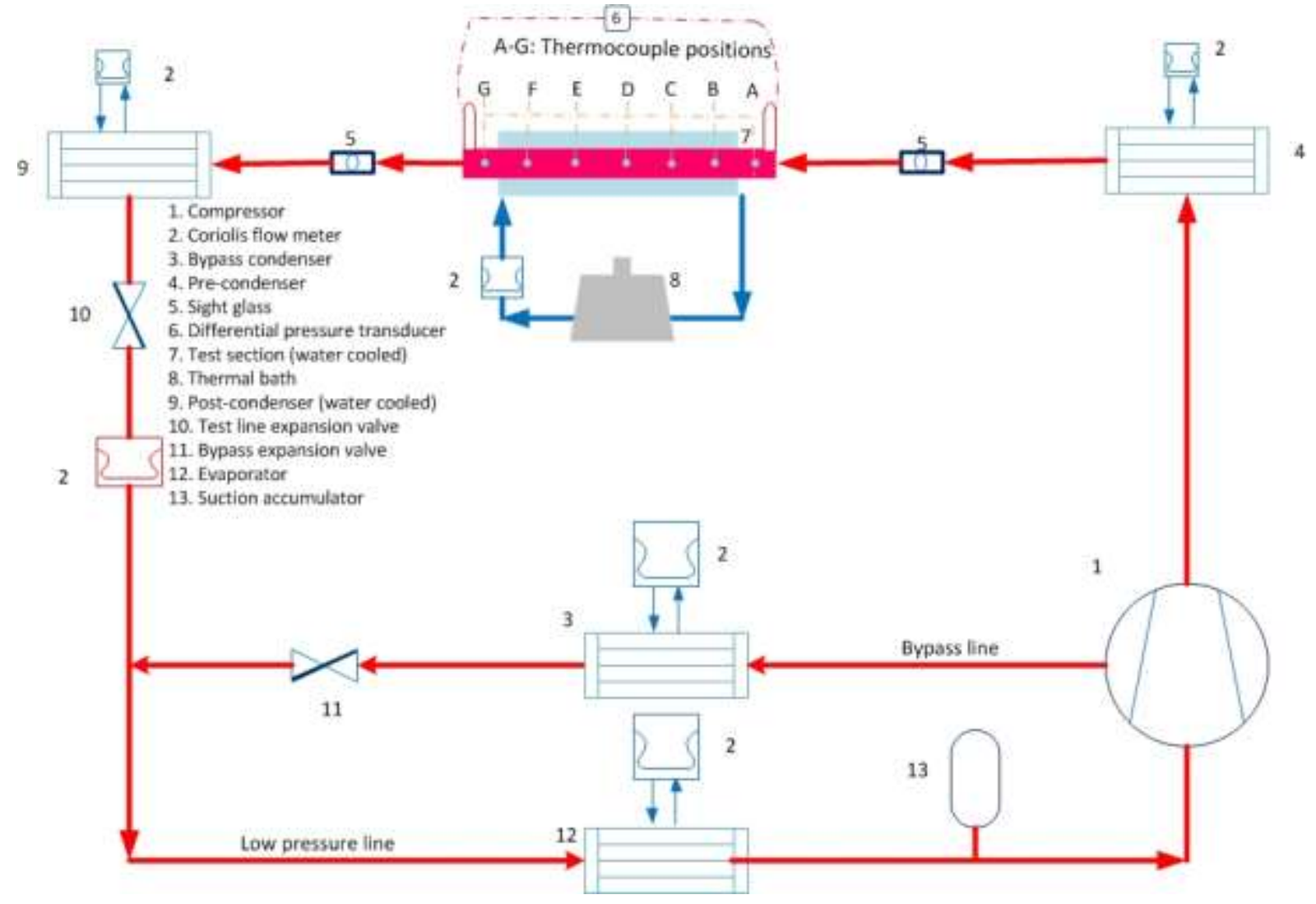

Figure 1. Schematic of the experimental set-up and test section.

The test line had three condensers: the pre-condenser, the test condenser containing the test section, and the post-condenser. The pre-condenser was used to control the inlet vapour quality into the test section where the actual measurements and experiments were conducted. The post-condenser was used to ensure that complete condensation and sub cooling occurred to ensure that only liquid flowed through the refrigerant mass flow meter. The bypass line had a bypass condenser that controlled the pressure, temperature, and mass flow rate of the refrigerant flowing into and through the test line. The majority of the refrigerant flowed through the bypass line with a smaller fraction through the test section line. The refrigerant from the two high pressure lines was throttled in the electronic expansion valves into the low pressure line, consisting of a water heated evaporator, suction accumulator, and a scroll compressor.

The water that was used for the pre-condenser, post-condenser, and evaporator was stored and supplied from two storage tanks with capacities of 500 litre each. These tanks were kept at pre- 
selected temperatures and were thermostatically controlled to approximately $15^{\circ} \mathrm{C}$ and $40^{\circ} \mathrm{C}$, respectively. These tanks were maintained at these constant temperatures because they were connected to a dual-function heat pump. The colder storage tank was connected to the pre- and postcondenser, and the warmer storage tank to the evaporator. A $1.5 \mathrm{~kW}$ thermal bath, with a 20 litre storage tank, was connected to the annulus of the test section. This thermal bath had a built-in pump and was operated with water inlet temperatures varying from $10^{\circ} \mathrm{C}$ to $20^{\circ} \mathrm{C}$, depending on the required condensation experiments required in the test section.

The test section was a smooth copper tube that was assembled to correspond to a tube-in-tube heat exchanger configuration. The inner tube formed the test section in which the refrigerant flowed. The flow of water in the annulus was in a counter direction to that of the refrigerant. The water in the annulus was always operated at a temperature lower than that of the refrigerant gas, and therefore, condensation occurred on the inside of the test section tube.

The rate of condensation in the test section tube was manipulated with the refrigerant and/or water mass flow rates streams. The refrigerant stream was controlled by changing its mass flow rate, saturation temperature, and inlet quality. The refrigerant mass flow rate was controlled by opening the test section expansion valve. This also influenced the saturation temperature and pressure of the test section which was controlled with the opening or closing of the expansion valve of the bypass line and the water mass flow rate through the bypass condenser. It was found that the saturation values were more sensitive to water mass flow rate changes than changing the opening of the electronic expansion valve. Therefore, the water mass flow rate changes were mostly used to manipulate the saturation values close to the required values, while the expansion valve was used for precision control.

The vapour quality of the refrigerant before and after the test section was carefully controlled, as the overall test quality was defined as the average quality between the inlet and outlet qualities of the test section. This required quality was controlled with the water inlet temperatures and mass flow rates 
flowing through the annulus of the test section and flowing through the pre-condenser of the test section.

In the water stream through the test section, the mass flow rate and water inlet temperature were controlled. The mass flow rate of the water was controlled by two means. The first was adjusting the pump setting of the thermal bath while the other was the use of servo-actuated values to control the flow through the test section while the remaining flow was bypassed to the bypass heat exchanger and immediately entered the return line back to the reservoirs. The water inlet temperature was set by changing the set point of the thermal bath. The refrigerant and water mass flow rates through the three condensers were measured with a Coriolis mass flow meter that could measure both the refrigerant and water mass flow rates with errors of less than $0.05 \%$

The test section inner tube was $1.5 \mathrm{~m}$ in length, with a measured inner diameter of $8.38 \mathrm{~mm}$ and an outer diameter of $9.54 \mathrm{~mm}$. The annulus outer tube had an inner diameter of $14.5 \mathrm{~mm}$ and an outer diameter of $15.88 \mathrm{~mm}$. The test section, pre-condenser, post-condenser, bypass-condenser, evaporator, and all refrigerant and water lines were insulated with $60 \mathrm{~mm}$ of a closed cell elastometric nitrile rubber that had a thermal conductivity of $0.039 \mathrm{~W} / \mathrm{mK}$ in order to minimise heat losses to and from the environment.

Two sight glasses were installed at the inlet and outlet of the test section. The sight glasses had the same inner diameter as the test section and were made from borosilicate. The purposes of the sight glasses were twofold. First, they were used to prevent axial conduction from the test section inner tube to the connecting tubes at the inlet and outlet, as the thermal conductivities $(1.2 \mathrm{~W} / \mathrm{mK})$ of the sight glasses were much lower than those of the copper tubes in the test section line. Second, they were used for visual observations, and to capture the flow patterns with video cameras. Videos were taken in grey levels. However, it was found that without a light emitting diode (LED), the flow could not be visualised properly as evidenced by a black cloud seen around the glass tube. Hence, to 
improve the image quality and ensure uniformity in the distribution of the light, a uniform (LED) backlight was used. This LED backlight was a $98.7 \%$ uniform, 50 by $50 \mathrm{~mm}$ red light. Furthermore, it was chosen to have a low energy output so that it did not thermally affect the passing flow. The flow regimes were captured with two different cameras. The camera at the inlet could capture videos at 200 frames per second, while the camera at the outlet was limited to 100 frames per second. Owing to the frames per second limitation of the video camera at the outlet, the quality of the outlet videos was not as good as that of the inlet.

To ensure that the flow through the test condenser was fully developed, a straight calming section, $500 \mathrm{~mm}$ in length, and of the same diameter as the test section, was positioned upstream of the entrance to the test section (after the sight glasses). Another calming section which was $400 \mathrm{~mm}$ long and of the same diameter as the test section was positioned at the exit of the test condenser to minimise the disturbance at the exit sight glass.

The absolute pressures at the inlet and outlet of the test sections were measured with absolute pressure transducers that were connected to pressure taps at the inlet and outlet of the test section. The inaccuracies of the absolute pressure measurements were $\pm 2 \mathrm{kPa}$. The pressure drop over the test section was measured with a calibrated differential pressure drop transducer, which was also connected to two different pressure taps at the inlet and outlet of the test section.

On the outside surface of the test section tube, 28 shallow holes were drilled at seven stations marked A to $\mathrm{G}$, as shown in Figure 1. The first station at $\mathrm{A}$ was at a distance of $70 \mathrm{~mm}$ from the inlet, and the subsequent spacing between all the other stations was $225 \mathrm{~mm}$. Each station had four shallow drilled holes at equal distances around the circumference. In each hole, a $1.3 \mathrm{~mm}$ diameter, T-type thermocouple used for outside wall temperature measurements was attached by soldering. The cooling water inlet and outlet temperatures were also measured as the average of three thermocouples mounted on the wall of the inlet and outlet of the annulus that surrounded the test section tube. The 
same was done with the average inlet and outlet water temperatures at the pre- and post-condensers. Care was taken to ensure that the mass flow rates of all cooling water channels were operated in the turbulent flow regime to ensure that the wall temperature measurement represented the average water temperatures. Fig. 2 shows a schematic of the measurement points in the test section.

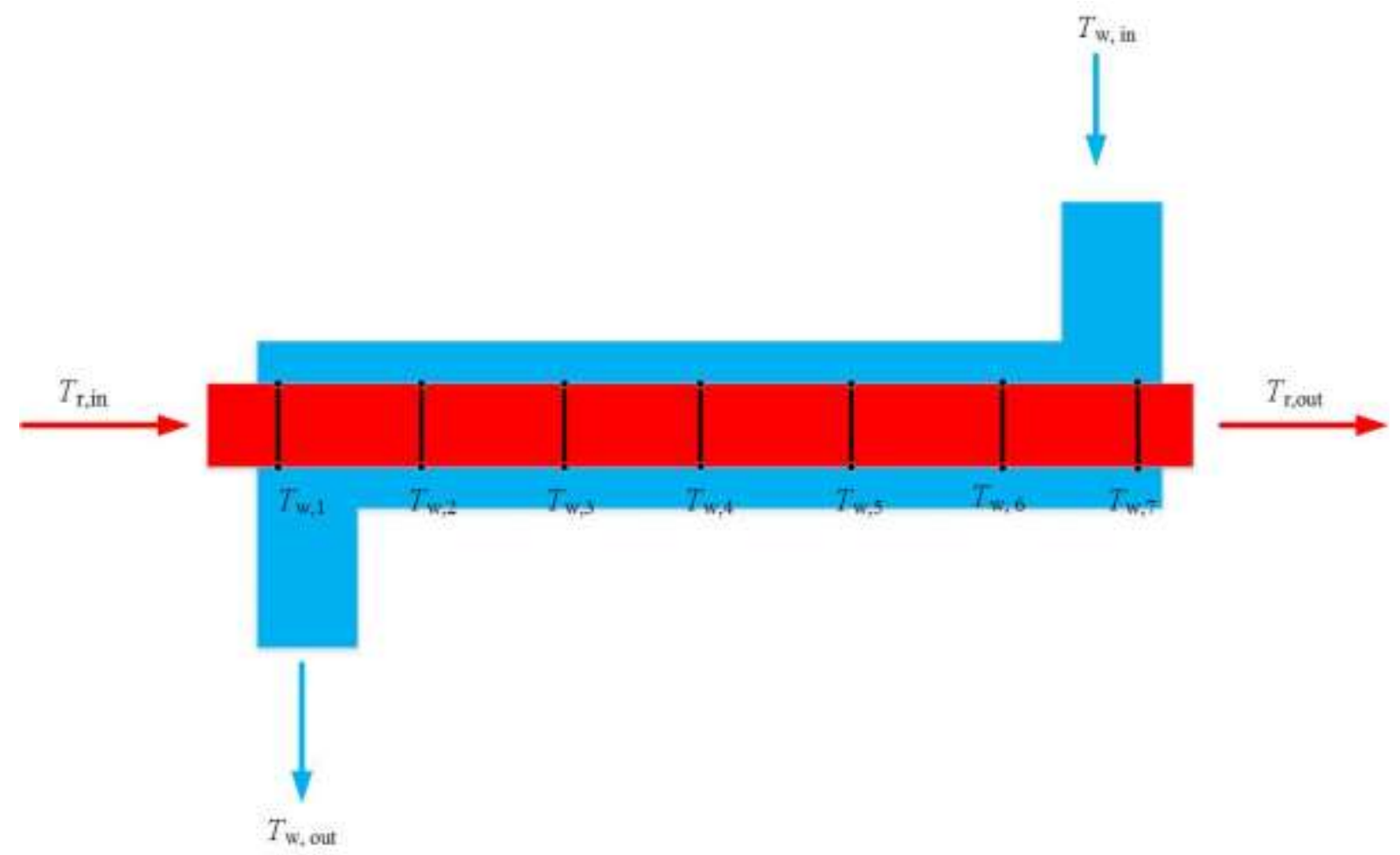

Figure 2. Schematic of the measurement points in the test section

The refrigerant temperatures were measured at four stations on the outside walls of the tubes. These were at the inlet and outlet of the test section, and at the inlet of the pre-condenser and outlet of the post condenser. These measurements were continuously correlated with the saturation temperatures indirectly obtained from the pressure measurements of the two absolute pressure transducers. These differences were never more than $0.1{ }^{\circ} \mathrm{C}$. All the thermocouples used were calibrated before the start of the experimental programme against a calibrated PT100 to an accuracy of $\pm 0.1^{\circ} \mathrm{C}$.

The refrigerant pressure at the inlet to the test condenser was measured with a strain gauge pressure transducer to an accuracy of $\pm 2 \mathrm{kPa}$ for mass fluxes between $50-100 \mathrm{~kg} / \mathrm{m}^{2} \mathrm{~s}$. To determine its accuracy, the measured pressure value was cross-checked with the corresponding saturation 
temperature on the condensation saturation curve provided by REFPROP [65]. The pressure drop across the test condenser was measured with a differential pressure transducer calibrated to an accuracy of $\pm 9 \mathrm{~Pa}$.

All measurements of temperatures, pressures, and mass flow rates were taken at steady state conditions. These measurements were taken when no more fluctuations of these measured values occurred for a period of five minutes, and the energy balance $(E B)$, as determined in Section 3, was less than 5\% and also constant for a period of five minutes. A summary of the operating conditions and average energy balances of all experiments are shown in Table 1. The energy balances of all experiments varied between a minimum of $0.2 \%$ and a maximum of $5.2 \%$. The average energy balance was $2.1 \%$ with a standard deviation of $1.2 \%$.

Table 1. Operating conditions and average energy balances for the experimental matrix

$\begin{array}{lllll}\text { Parameter } & \text { Average } & \text { Minimum } & \text { Maximum } & \text { Standard deviation } \\ \text { Condensation temperature } & 40.0^{\circ} \mathrm{C} & 39.6{ }^{\circ} \mathrm{C} & 40.5{ }^{\circ} \mathrm{C} & 0.28^{\circ} \mathrm{C} \\ \text { Saturation pressure } & 1052 \mathrm{kPa} & 1031 \mathrm{kPa} & 1074 \mathrm{kPa} & 9.8 \mathrm{kPa} \\ \text { Energy balance } & 2.1 \% & 0.2 \% & 5.2 \% & 1.2 \%\end{array}$

All measurements were collected with a data acquisition arrangement which comprised of a desktop computer with LabVIEW software. Furthermore, embedded in the data acquisition system were terminal blocks, channel multiplexers, termination units, transducer multiplexers, an interface card, and signal-conditioning extensions for instrumentation. The readings were captured for $360 \mathrm{~s}$ (201 points) at $0.56 \mathrm{~Hz}$, and the averages of all 201 measurements were used. The standard deviations of the 201 points were monitored continuously.

At low refrigerant mass fluxes, the heat transfer rates were very low, and it was, therefore, very challenging to take a large number of measurements, as it took at least 90 minutes before steady state 
conditions were reached once a small adjustment was made to obtain data at another experimental point. Furthermore, the required temperature differences between the condensing wall and refrigeration saturation temperature that varied between $3-10^{\circ} \mathrm{C}$, was carefully adjusted with errors of less than $\pm 0.1^{\circ} \mathrm{C}$. The required inlet qualities were also carefully adjusted so that the errors in inlet qualities were less than 5\%. When the system was shut down and restarted, it took approximately two hours before steady state conditions were reached for the first time and the first experiment of the day could be conducted.

The oil concentration in the refrigerant was measured by Suliman et al. [30] in a previous study using the ASHRAE Standard [66] and was determined as $1.8 \%$ on average. The maximum measured was $2.3 \%$ and only occurred at much higher mass fluxes of $700 \mathrm{~kg} / \mathrm{m}^{2} . \mathrm{s}$, which was much higher than the range considered in this study. In these studies, it was shown that the of presence oil had a negligible effect on the results presented.

\section{Data reduction}

The heat transfer rate, $\dot{Q}_{r, p r e}$, of the condensing refrigerant was assumed to be equal to the water side heat transfer rate, $\dot{Q}_{w, p r e}$ (Eq. (1)). It was determined from the measured water mass flow rate, $\dot{m}_{w, p r e}$, through the pre-condenser and the measured average water inlet, $T_{w, p r e-i n}$, and outlet temperatures, $T_{w, p r e-o u t}$ :

$\dot{Q}_{w, p r e}=\dot{Q}_{r, p r e}=\dot{m}_{w, p r e} C_{p, w}\left(T_{w, p r e-o u t}-T_{w, p r e-i n}\right)$

The specific heat values of the water, $C_{p, w}$, were obtained from REFPROP [65] using the average of the measured inlet- and outlet water temperatures through the pre-condenser. The heat transfer rates through the test section and post-condensers were determined similarly: 
$\dot{Q}_{w, t e s t}=\dot{Q}_{r, t e s t}=\dot{m}_{w, t e s t} C_{p, w}\left(T_{w, t e s t-o u t}-T_{w, t e s t-i n}\right)$

and

$\dot{Q}_{w, p o s t}=\dot{Q}_{r, p o s t}=\dot{m}_{w, p o s t} C_{p, w}\left(T_{w, p o s t-o u t}-T_{w, p o s t-i n}\right)$

The enthalpy value of the refrigerant at the outlet of the pre-condenser, $h_{r, p r e-o u t}$, was determined as

$\dot{Q}_{w, p r e}=\dot{m}_{r, p r e}\left(h_{r, p r e-i n}-h_{r, p r e-o u t}\right)$

The value of $h_{r, p r e-o u t}$ could be determined from Eq. (4), as $\dot{Q}_{w, p r e}$ was determined from Eq. (1). $\dot{m}_{r, p r e}$ was the measured mass flow rate of the refrigerant through the pre-condenser, and $h_{r, p r e-i n}$ was the specific enthalpy of the refrigerant at the inlet to the pre-condenser (acquired from REFPROP [65] using the measured temperature and pressure conditions at the inlet to the pre-condenser).

The enthalpy values of the refrigerant at the outlet of the test-condenser, $h_{r, \text { test-out }}$, and outlet of post-condenser, $h_{r, \text { post-out }}$, were determined similarly:

$\dot{Q}_{w, \text { test }}=\dot{m}_{r, \text { test }}\left(h_{r, \text { test-in }}-h_{r, \text { test-out }}\right)$

and

$\dot{Q}_{w, \text { post }}=\dot{m}_{r, \text { post }}\left(h_{r, \text { post }- \text { in }}-h_{r, \text { post-out }}\right)$ 
As the post condenser was always operated to ensure fully condensed liquid at its outlet, the outlet enthalpy values, $h_{r, p o s t-o u t}$, determined from Eq. (6) were cross-checked with enthalpy values obtained from REFPROP [65] using the measured refrigerant pressure and temperatures values at the exit of the pre-condenser.

The total water side heat transfer rate, $\dot{Q}_{w, t o t}$, was determined as

$\dot{Q}_{w, t o t}=\dot{Q}_{w, p r e}+\dot{Q}_{w, t e s t}+\dot{Q}_{w, p o s t}$

while the total condensing refrigerant heat transfer rate, $\dot{Q}_{r, t o t}$, was determined as

$\dot{Q}_{r, t o t}=\dot{m}_{r}\left(h_{r, p r e-i n}-h_{r, p o s t-o u t}\right)$

In Eq. (8), $\dot{m}_{r}$ was the measured refrigerant mass flow rate through the test line, which was the same refrigerant mass flow rate through the pre-condenser as well as through the post-condenser; thus, $\dot{m}_{r}=\dot{m}_{r, p r e}=\dot{m}_{r, t e s t}=\dot{m}_{r, p o s t}$

The relative differences in heat transfer rates between the water and refrigerant sides were then compared in the format of an energy balance $(E B)$ as follows:

$E B=\frac{\left|\dot{Q}_{r, t o t}-\dot{Q}_{w, t o t}\right|}{\dot{Q}_{r, t o t}}$

The inlet vapour qualities, $x_{i n}$, of the refrigerant at the test section inlet were determined as 
$x_{i n}=\frac{h_{r, t e s t-i n}-h_{l}}{h_{v}-h_{l}}$

The saturated vapour and liquid values of the specific enthalpies, $h_{v}$ and $h_{l}$, respectively, were obtained from REFPROP using the average of the measured test section inlet and outlet refrigerant temperatures, and/or average of the measured inlet and outlet refrigerant absolute pressures. It was found that the values obtained from either the measured pressures and temperatures correlated to saturation temperature differences of less than $0.1^{\circ} \mathrm{C}$ from each other.

The outlet vapour qualities, $x_{\text {out }}$, of the refrigerant at the test section outlet were determined similarly as

$x_{\text {out }}=\frac{h_{r, \text { test }- \text { out }}-h_{l}}{h_{v}-h_{l}}$

With the inlet and outlet qualities of the test section known, the mean qualities, $x_{m}$, were taken as the average between the inlet and outlet qualities:

$x_{m}=\frac{x_{o u t}+x_{i n}}{2}$

For all experiments, while the enthalpies and qualities were determined, the outside wall temperatures, $\bar{T}_{w, o}$, were determined as the average measured wall temperatures obtained from the trapezium integration technique of the 28 thermocouple measurements at seven different stations (Fig. 2) on the outside of the tube. 
$\bar{T}_{w, o}=\frac{1}{L} \sum_{j=1}^{7}\left[\left(T_{w, o}^{j}+T_{w, o}^{j+1}\right)\left(z_{j+1}-z_{j}\right)\right]$

At each of the seven stations, the average station temperatures were taken as the average of the four thermocouple measurements around the perimeter of the test section tube.

The average temperatures on the inside of the test section wall, $\bar{T}_{w, i}$, were determined by using the outside wall tube temperature measurements, $\bar{T}_{w, o}$, and taking into consideration the heat transfer rate through the wall, $\dot{Q}_{w, t e s t}$, and the thermal wall resistance, $R_{w}$, of the wall:

$\bar{T}_{w, i}=\bar{T}_{w, o}+\left|\dot{Q}_{w, t e s t} R_{w}\right|$

The thermal wall resistance was determined as

$R_{w}=\frac{\ln \left(d_{o} / d_{i}\right)}{2 \pi k_{c u} L}$

where $d_{o}$ and $d_{i}$ were respectively the measured outside and inside diameters of the test section, $k_{c u}$ was the thermal conductivity of the test section which was made from copper, and the measured length, $L$, of the test section tube.

It was found that the wall thermal resistances were negligible in all cases, as the differences between the inside and outside tube walls were all less than the errors $\left(0.1^{\circ} \mathrm{C}\right)$ of the temperature measurements. Therefore, it was found that the average wall temperature measurements in Eq. (13) on the outside of the wall were equal to the inside wall temperatures required in Eq. (14). 
The "temperature differences" referred to in this paper used for the heat transfer coefficient calculations were

$\Delta T=T_{s a t}-\bar{T}_{w, i}$

They referred to the temperature difference between the refrigerant saturation temperatures, $T_{\text {sat }}$, and average wall inner temperatures, $\bar{T}_{w, i}$, of the test section determined by Eq. (14). The saturation temperatures were taken as the average between the measured inlet, $T_{r, \text { in }}$ and outlet refrigerant temperature $T_{r, \text { oot }}$, measurements of the test section (Fig. 2). This saturation temperature also corresponded to within $0.1^{\circ} \mathrm{C}$ of the saturation temperature that was implicitly determined from REFPROP when the measured absolute saturation pressure measurements taken from the average of the inlet and outlet test section pressure measurements were used.

With the heat transfer rates known, the average heat transfer coefficients, $\alpha$, of the condensing refrigerant in the test section were determined as

$\alpha=\frac{\dot{Q}_{w, t e s t}}{A_{i} \Delta T}$

The heat transfer rates, $\dot{Q}_{w, t e s t}$, of the water side of the test section were used to determine the heat transfer coefficients, not the refrigerant heat transfer rates, $\dot{Q}_{r, t e s t}$. The uncertainties of the refrigerant rate depended on the uncertainties of the inlet and outlet enthalpies whose uncertainties further depended on the uncertainties of the inlet and outlet vapour qualities which were approximately $5 \%$. However, the uncertainties of the heat transfer rate on the water side, $\dot{Q}_{w, t e s t}$, was $3 \%$. The internal surface area $\left(A_{i}=\pi d_{i} L\right)$ of the test section of the heat transfer tube was determined from the measured tube inlet diameter $d_{i}$, which was $8.38 \mathrm{~mm}$, and measured test section length over which heat transfer occurred, $L$, which was $1.5 \mathrm{~m}$. 
Lastly, since the heat transfer coefficients were mass flux dependant, the corresponding mass fluxes were determined as

$G=\frac{\dot{m}_{r, t e s t}}{A_{C S}}$

where the test section cross sectional area was determined as $A_{c S}=(\pi / 4) d_{i}^{2}$.

\section{Uncertainty analysis and repeatability}

An uncertainty analysis was conducted as prescribed by Dunn [67], based on the experimental parameters and uncertainties given in Table 2. The results showed that, in the range over which experiments were conducted, the uncertainties were $1 \%, 5 \%$, and $10 \%$ for the mass fluxes, qualities, and heat transfer coefficients, respectively, at a specific mean quality. Two challenges were encountered during the generation of results. First, because of the low mass fluxes, the heat transfer rates in the test section were low, and varied as low as $170 \mathrm{~W}$. Second, in many cases, the changes in quality values from the inlet to outlet were significant. This can be solved by using a shorter test section length. However, then the heat transfer rates decrease even further and the uncertainties would increase significantly. For example, decreasing the test section length by $50 \%$, would have increased the uncertainties of the heat transfer coefficients to $18 \%$.

Table 2. Experimental parameters, ranges, and uncertainties

$\begin{array}{lll}\text { Parameter } & \text { Range } & \text { Uncertainties } \\ T_{\text {sat }} & 40^{\circ} \mathrm{C} & \pm 0.1^{\circ} \mathrm{C} \\ G & 50-200 \mathrm{~kg} / \mathrm{m}^{2} \mathrm{~s} & \pm 1 \% \\ x_{m} & 0.1-0.9 & \pm 5 \% \\ \alpha & 1300-2200 \mathrm{~W} / \mathrm{m}^{2} \mathrm{~K} & \pm 11 \% \\ \dot{Q}_{w} & 170-600 \mathrm{~W} & \pm 1 \%\end{array}$


The repeatability of the measured results of the condensation heat transfer coefficients was established by repeating a selection of approximately $60 \%$ of the results three months later. The maximum percentage differences of the heat transfer coefficients and qualities when the experiments were repeated was about $2 \%$. This maximum difference was found at vapour qualities below 0.25 .

\section{Validation of experimental set-up}

A validation study was carried out to confirm the functionality and accuracy of the experimental setup and the data generated from it. A summary of the validation test matrix is shown in Table 3 , and it identifies the 25 different conditions that were used for experimental comparison purposes. The validation experiments were conducted at a saturation temperature of $40^{\circ} \mathrm{C}$ over a mass flux range of $100-400 \mathrm{~kg} / \mathrm{m}^{2} \mathrm{~s}$ at qualities of $0.1-0.9$. It was found that, for all these experiments, the heat transfer coefficients compared well to literature: the average deviation of the 25 heat transfer coefficients with the literature was $8 \%$, the maximum deviation was $15 \%$, and a minimum deviation was $1 \%$. The results of a part of the validation experiments are summarised in Figure 3.

Table 3. Summary of validation heat transfer coefficient experiments conducted at different qualities

$\begin{array}{rrrrrrrrl}\boldsymbol{G}\left[\mathrm{kg} / \mathbf{m}^{2} \mathbf{s}\right] & \boldsymbol{x}_{m}[-] & \boldsymbol{x}_{m}[-] & \boldsymbol{x}_{m}[-] & \boldsymbol{x}_{m}[-] & \boldsymbol{x}_{m}[-] & \boldsymbol{x}_{m}[-] & \boldsymbol{x}_{m}[-] & \text { Number of data points } \\ 100 & 0.1 & 0.2 & 0.35 & 0.5 & 0.62 & 0.75 & 0.9 & 7 \text { points } \\ 200 & 0.1 & 0.2 & - & 0.5 & 0.62 & 0.75 & 0.9 & 6 \text { points } \\ 300 & 0.1 & 0.2 & - & 0.5 & 0.62 & 0.75 & 0.9 & 6 \text { points } \\ 400 & 0.1 & 0.2 & - & 0.5 & 0.62 & 0.75 & 0.9 & 6 \text { points }\end{array}$

Total $=25$ points

In Figure 3, the results are given at a mass flux of $300 \mathrm{~kg} / \mathrm{m}^{2} \mathrm{~s}$, and were compared to the measurements of Cavallini et al. [34], Jung et al. [21], Kim and Shin [22], Lips and Meyer [18], Meyer et al. [20], Suliman et al. [30], and Van Rooyen et al. [25]. In general, the measurements compared well to measurements from literature. The measurements were lower than the measurements of Cavallini et al., Van Rooyen et al., Jung et al., and Kim and Shin, but higher than 
those of Suliman et al. The mean deviations were $16 \%$ lower than the values of Cavallini et al., and $11 \%$ higher than those of Suliman et al.

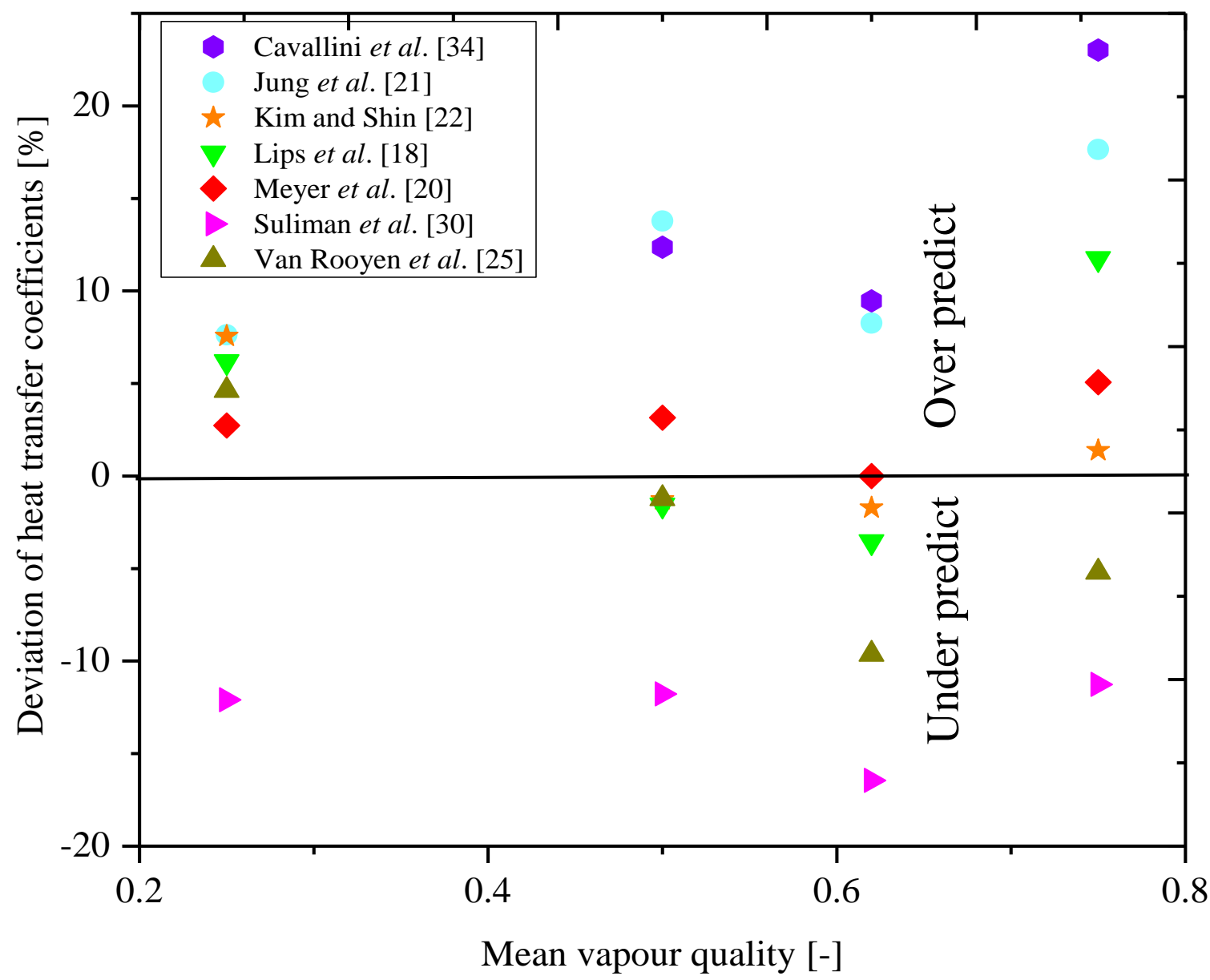

Figure 3. Validation results of experimental heat transfer coefficients as functions of quality at a mass flux of $300 \mathrm{~kg} \cdot \mathrm{m}^{2} / \mathrm{s}$ compared to experimental data at a saturation temperature of $40^{\circ} \mathrm{C}$.

A verification at mass fluxes lower than $100 \mathrm{~kg} / \mathrm{m}^{2} \mathrm{~s}$, which would have been desirable, was not possible, and for that reason, verifications were conducted in this section on mass fluxes of only 100$400 \mathrm{~kg} / \mathrm{m}^{2} \mathrm{~s}$. Specific verifications against the work of others at low mass fluxes were not possible because of differences in refrigerants [4, 9-11], tube diameter [37], tube shape [13], orientation (vertical and not horizontal) [23, 26], and temperature differences not specified [30]. Moreover, the other studies $[1-3,5,6,15,26,28,35,68]$ were general reviews with no experimental results to show. The only direct comparison that could have been possible against previous work was with the work of Suliman et al. [30], in which two heat transfer coefficients at a heat flux of $75 \mathrm{~kg} / \mathrm{m}^{2} \mathrm{~s}$ were 
determined; however, the temperature differences at which the measurements were made were not specified.

Figure 4 summarises the only two flow patterns observed in the study. These flow patterns, which were stratified (S) flow and stratified wavy (SW) flow, were adopted using the definitions and descriptions of flow regimes prescribed by Thome [7]. All the experimental data points summarized in Table 3 were also compared to the Thome [49] flow regime map. It was found that the observed flow regimes were in all cases correctly predicted.

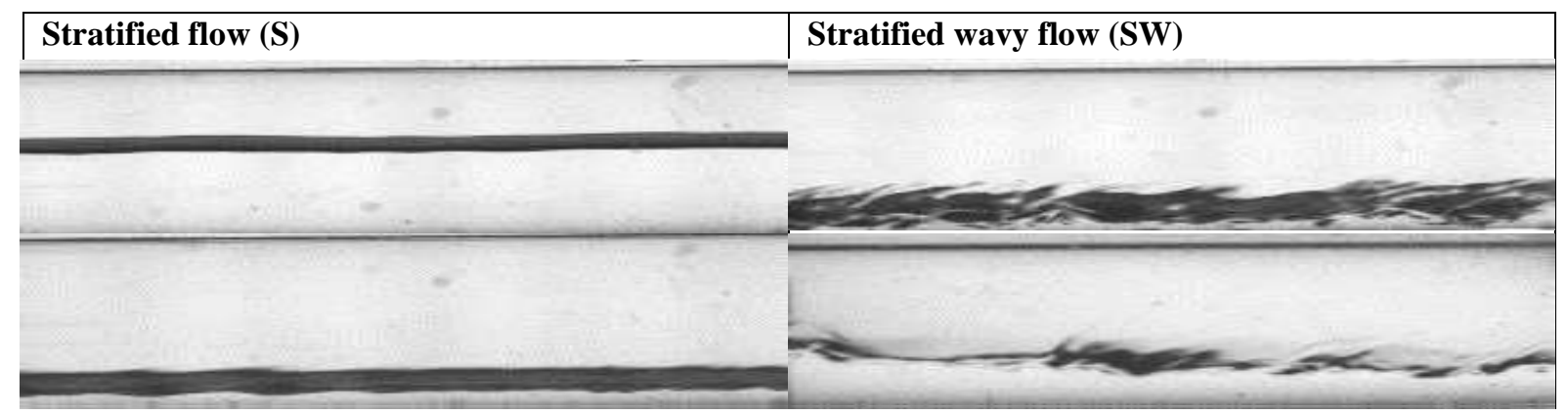

Figure 4. General description of flow patterns found in the study at mass fluxes of 50, 75, and $100 \mathrm{~kg} \cdot \mathrm{m}^{2} / \mathrm{s}$

In general, although extensive verification experiments at mass fluxes lower than $100 \mathrm{~kg} / \mathrm{m}^{2} \mathrm{~s}$ were not possible (results at a mass flux of $100 \mathrm{~kg} / \mathrm{m}^{2} \mathrm{~s}$ are presented in the following section), the agreement of heat transfer coefficients and flow regime observations at mass fluxes from $100-400 \mathrm{~kg} / \mathrm{m}^{2} \mathrm{~s}$ were satisfactory, and at least verifications were conducted at a mass flux of $100 \mathrm{~kg} / \mathrm{m}^{2} \mathrm{~s}$, which was on the upper boundary of the range of mass fluxes considered in the following section. 
Table 4. Summary of experimental test points at different operating conditions of mass flux, temperature difference, and quality

\begin{tabular}{|c|c|c|c|c|}
\hline \multirow[b]{2}{*}{ Mean vapour quality } & \multicolumn{4}{|c|}{$G=150$ and $200 \mathrm{~kg} / \mathrm{m}^{2} \mathrm{~s}$} \\
\hline & $\Delta T=3^{\circ} \mathrm{C}$ & $\Delta T=5^{\circ} \mathrm{C}$ & $\Delta T=8^{\circ} \mathrm{C}$ & $\Delta T=10^{\circ} \mathrm{C}$ \\
\hline$x_{m}$ & 0.1 & 0.1 & 0.1 & 0.1 \\
\hline$x_{m}$ & 0.25 & 0.25 & 0.25 & 0.25 \\
\hline$x_{m}$ & 0.5 & 0.5 & 0.5 & 0.5 \\
\hline$x_{m}$ & 0.62 & 0.62 & 0.62 & 0.62 \\
\hline$x_{m}$ & 0.75 & 0.75 & 0.75 & 0.75 \\
\hline$x_{m}$ & 0.9 & 0.9 & 0.9 & 0.9 \\
\hline
\end{tabular}

Sub-total $=48$ points

$$
G=100 \mathrm{~kg} / \mathrm{m}^{2} \mathrm{~s}
$$

\section{Mean vapour quality}

$\Delta T=3^{\circ} \mathrm{C}$

$\Delta T=5^{\circ} \mathrm{C}$

$\Delta T=8^{\circ} \mathrm{C}$

$\Delta T=10^{\circ} \mathrm{C}$

$x_{m}$

0.1

0.15

0.25

0.3

$\boldsymbol{x}_{\boldsymbol{m}}$

0.17

0.22

0.3

0.4

0.25

0.25

0.35

0.45

0.41

0.3

0.41

0.52

0.45

0.35

0.43

0.62

$\boldsymbol{x}_{\boldsymbol{m}}$

0.60

0.38

0.5

0.75

0.41

0.55

0.82

0.5

0.62

0.55

0.6

$G=75 \mathrm{~kg} / \mathrm{m}^{2} \mathrm{~s}$

$\begin{array}{llll}\text { Mean vapour quality } & \boldsymbol{\Delta} \boldsymbol{T = 3 ^ { \mathbf { 0 } } \mathbf { C }} & \boldsymbol{\Delta} \boldsymbol{T}=\mathbf{5}^{\mathbf{0}} \mathbf{C} & \boldsymbol{\Delta} \boldsymbol{T}=\mathbf{8}^{\mathbf{0}} \mathbf{C} \\ \boldsymbol{x}_{\boldsymbol{m}} & 0.25 & 0.25 & 0.3 \\ \boldsymbol{x}_{\boldsymbol{m}} & 0.3 & 0.5 & 0.5 \\ \boldsymbol{x}_{\boldsymbol{m}} & 0.43 & 0.62 & 0.62 \\ \boldsymbol{x}_{\boldsymbol{m}} & 0.5 & & \\ \boldsymbol{x}_{\boldsymbol{m}} & 0.62 & & \end{array}$

Sub-total=31 points

Sub-total=11 points

$\begin{array}{lll} & & \boldsymbol{G}=\mathbf{5 0} \mathrm{kg} / \mathrm{m} \\ \text { Mean vapour quality } & \boldsymbol{\Delta} \boldsymbol{T = \mathbf { 3 } ^ { \mathbf { 0 } } \mathrm { C }} & \boldsymbol{\Delta} \boldsymbol{T = 5 ^ { \mathbf { 0 } } \mathrm { C }} \\ \boldsymbol{x}_{\boldsymbol{m}} & 0.25 & 0.35 \\ \boldsymbol{x}_{\boldsymbol{m}} & 0.35 & 0.5 \\ \boldsymbol{x}_{\boldsymbol{m}} & 0.62 & 0.62 \\ \boldsymbol{x}_{\boldsymbol{m}} & 0.75 & \end{array}$

\section{Sub-total $=7$ points}

Total $=97$ points

\section{Results}

Table 4 shows the test matrix of the experiments that were carried out at mass fluxes of 200, 150, 100, 75 and $50 \mathrm{~kg} / \mathrm{m}^{2} \mathrm{~s}$ at different temperature differences, $\Delta T$, and average qualities, $x_{m}$. A total of 97 
experimental data points were produced. The average saturation temperature of all the measurements conducted was at a condensing temperature of $40^{\circ} \mathrm{C}$, with a standard deviation of just less than approximately $0.3^{\circ} \mathrm{C}$.

At a mass flux of $200 \mathrm{~kg} / \mathrm{m}^{2} \mathrm{~s}, 24$ measurements were taken at six different qualities of $0.10,0.25$, $0.50,0.62,0.75$, and 0.9 , and at four different temperature differences of $3,5,8$, and $10^{\circ} \mathrm{C}$. At a mass flux of $150 \mathrm{~kg} / \mathrm{m}^{2} \mathrm{~s}, 24$ measurements were taken at the same experimental conditions as those taken at $200 \mathrm{~kg} / \mathrm{m}^{2} \mathrm{~s}$. At mass fluxes of $100 \mathrm{~kg} / \mathrm{m}^{2} \mathrm{~s}, 75 \mathrm{~kg} / \mathrm{m}^{2} \mathrm{~s}$, and $50 \mathrm{~kg} / \mathrm{m}^{2} \mathrm{~s}$, the number of experimental conditions at which experiments were conducted was 31,11 , and 7 , respectively. The experimental conditions at which experiments could be conducted therefore decreased with mass flux. This was because the changes in quality from the test section inlet to outlet increased. To prevent this from occurring, the mass flow rate through the water in the annulus and/or water inlet temperature to the annulus can be altered. However, it has been found that the heat transfer rates became too low, and the uncertainties of the heat transfer coefficients became too high.

\subsection{Flow patterns}

In Figs. 5 to 7, the captured flow patterns at the test section inlet and outlet at different mean qualities (average between the inlet and outlet qualities) are given at three different mass fluxes $100 \mathrm{~kg} / \mathrm{m}^{2} \mathrm{~s}$ (Fig. 5), $75 \mathrm{~kg} / \mathrm{m}^{2} \mathrm{~s}$ (Fig. 6), and $50 \mathrm{~kg} / \mathrm{m}^{2} \mathrm{~s}$ (Fig. 6).

In Fig. 5, at a mass flux of $100 \mathrm{~kg} / \mathrm{m}^{2} \mathrm{~s}$, a mean vapour quality of 0.15 , and temperature difference of $3^{\circ} \mathrm{C}$, the inlet vapour quality was 0.27 and the outlet vapour quality was 0.03 . The flow pattern visualisation showed that, at the test section inlet, the flow pattern was stratified wavy (SW), and at the tests section outlet, the flow pattern was stratified (S). As the flow pattern changed from the test section inlet to outlet, an "averaged" phenomenon that corresponds to an average quality of 0.15 was observed (hereafter referred to in this paper as a "SW-S" flow pattern). Although this SW-S flow pattern occurred only at an average quality of 0.15 for a $3^{\circ} \mathrm{C}$ temperature difference, it also occurred at temperature differences of $5^{\circ} \mathrm{C}, 8^{\circ} \mathrm{C}$, and $10^{\circ} \mathrm{C}$. Moreover, it was not only observed at an average 


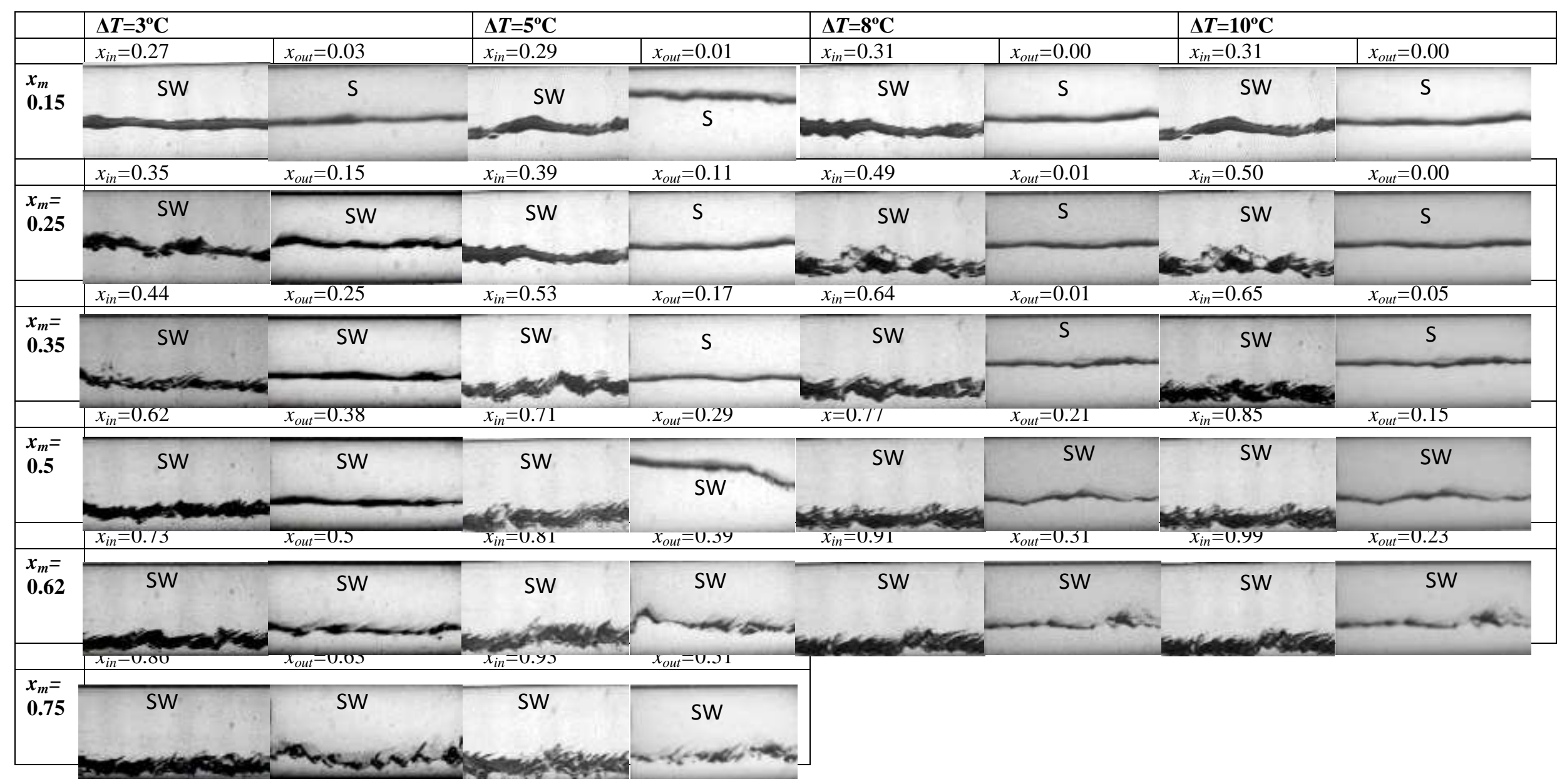

Figure 5. Flow regimes at different temperature differences and vapour qualities at a mass flux of $100 \mathrm{~kg} . \mathrm{m}^{2} / \mathrm{s}$. 


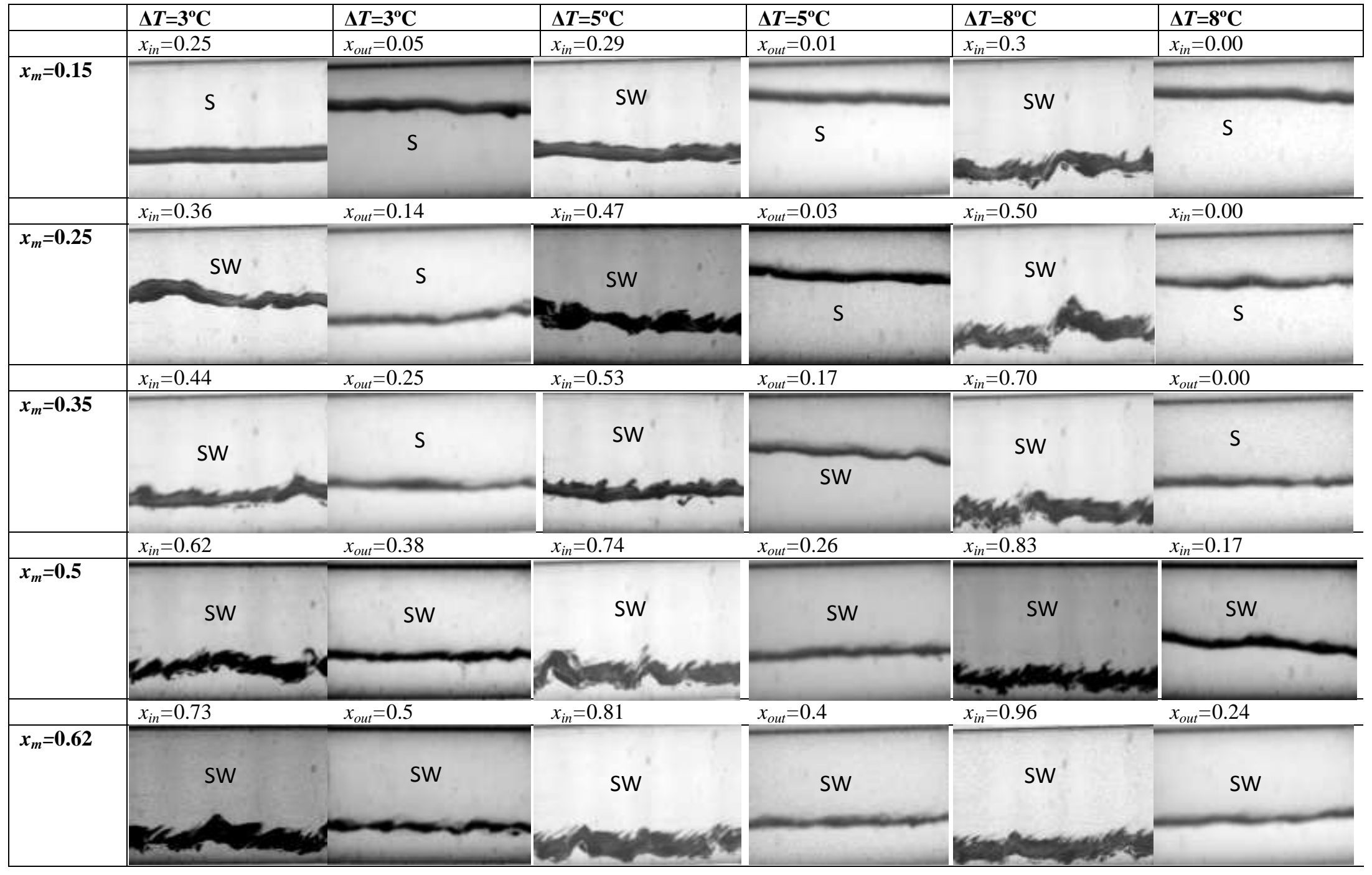

Figure 6. Flow regimes at different temperature differences and vapour qualities at a mass flux of $75 \mathrm{~kg} / \mathrm{m}^{2} \mathrm{~s}$. 


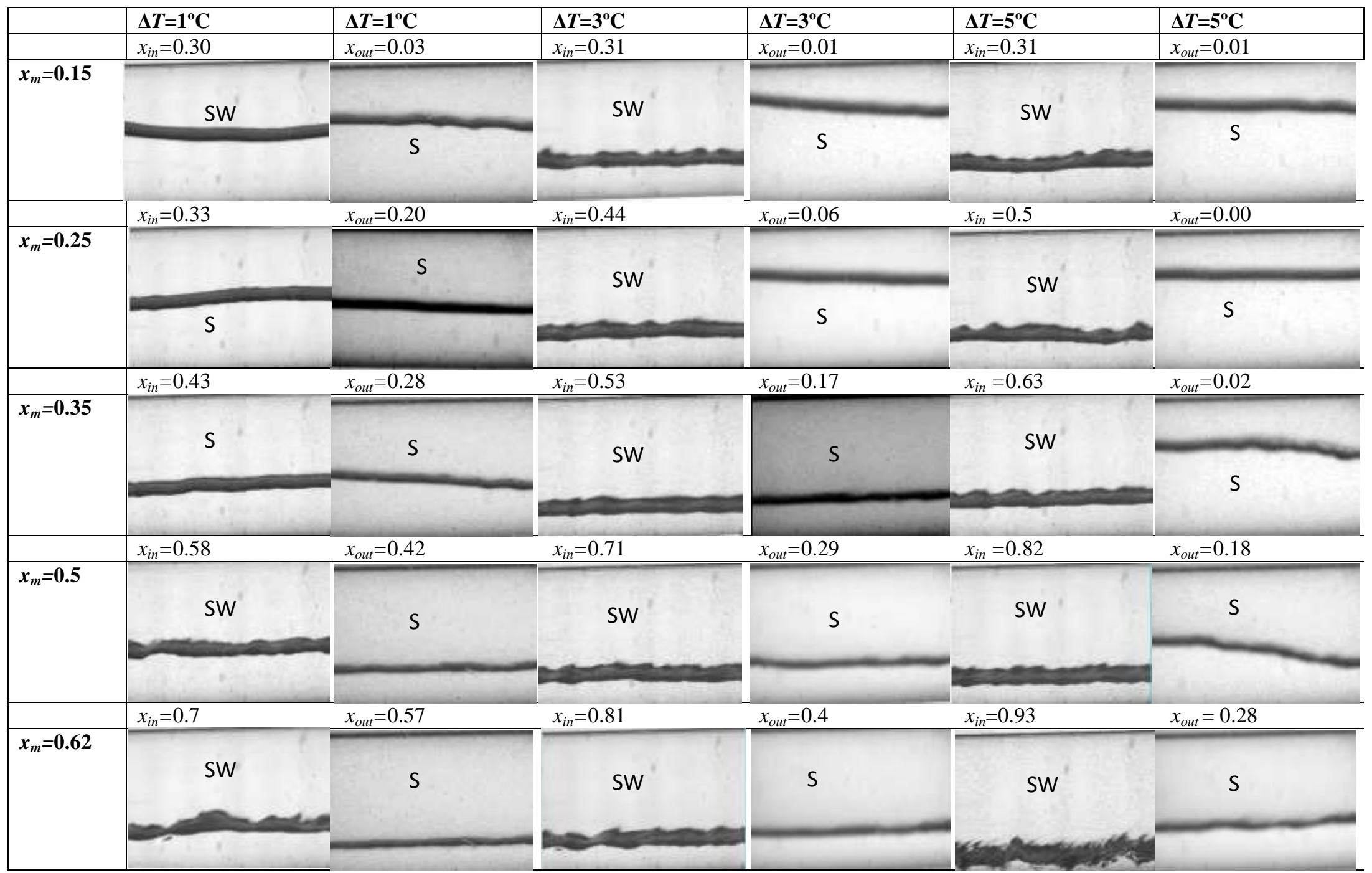

Figure 7. Flow regimes at different temperature differences and vapour qualities at a mass flux of $50 \mathrm{~kg} / \mathrm{m}^{2} \mathrm{~s}$ 
quality of 0.15 , but also at average qualities of 0.25 and 0.35 . Except for the SW-S flow patterns that were identified, all the other flow patterns in Fig. 5 at a mass flux of $100 \mathrm{~kg} / \mathrm{m}^{2} \mathrm{~s}$ were stratified wavy.

At a lower mass flux of $75 \mathrm{~kg} / \mathrm{m}^{2} \mathrm{~s}$ (Fig. 6), stratified flow occurred at both the inlet and outlet for the case of a temperature difference of $3{ }^{\circ} \mathrm{C}$ and an average quality of 0.15 , while all the other flow regimes were stratified wavy. The exceptions were SW-S regimes that occurred at the following temperatures and average qualities: (a) a temperature difference of $3^{\circ} \mathrm{C}$ and average qualities of 0.25 and 0.35 ; (b) a temperature difference of $5^{\circ} \mathrm{C}$ and average qualities of 0.15 and 0.25 ; and (c) a temperature difference of $8^{\circ} \mathrm{C}$ and average qualities of $0.15,0.25$, and 0.35 .

In Fig. 7, at a mass flux of $50 \mathrm{~kg} / \mathrm{m}^{2} \mathrm{~s}$, all the flow regimes for temperature differences of $1^{\circ} \mathrm{C}, 3^{\circ} \mathrm{C}$, and $5^{\circ} \mathrm{C}$ were found to be in general SW-S. The exceptions were at qualities of 0.25 and 0.35 , where the flow regimes were stratified. A debatable point occurred at $1{ }^{\circ} \mathrm{C}$ at an inlet quality of 0.30 . Although it was observed to be closer to stratified than stratified wavy, the general tendency of results indicates that it should be stratified.

The different flow regimes observed at the determined inlet and outlet qualities were plotted onto the relevant part of the El-Hajal et al. map [49], as shown in Fig. 8. The effects of temperature differences are also shown. This excludes the SW-S points, as the "averaging" of these points that specifically correspond to the average qualities listed in Figs. 5-7 are not accurate. The reason is that the transition from the stratified wavy regimes to the stratified regimes could have occurred anywhere between the inlet and outlet quality values.

For mass fluxes of $50 \mathrm{~kg} / \mathrm{m}^{2} \mathrm{~s}, 75 \mathrm{~kg} / \mathrm{m}^{2} \mathrm{~s}$, and $100 \mathrm{~kg} / \mathrm{m}^{2} \mathrm{~s}$, the map predicts that the transition vapour quality from stratified to stratified wavy flow should be $0.29,0.17$, and 0.11 , respectively. At a mass flux of $100 \mathrm{~kg} / \mathrm{m}^{2} \mathrm{~s}$, all the flow regimes were predicted correctly. 


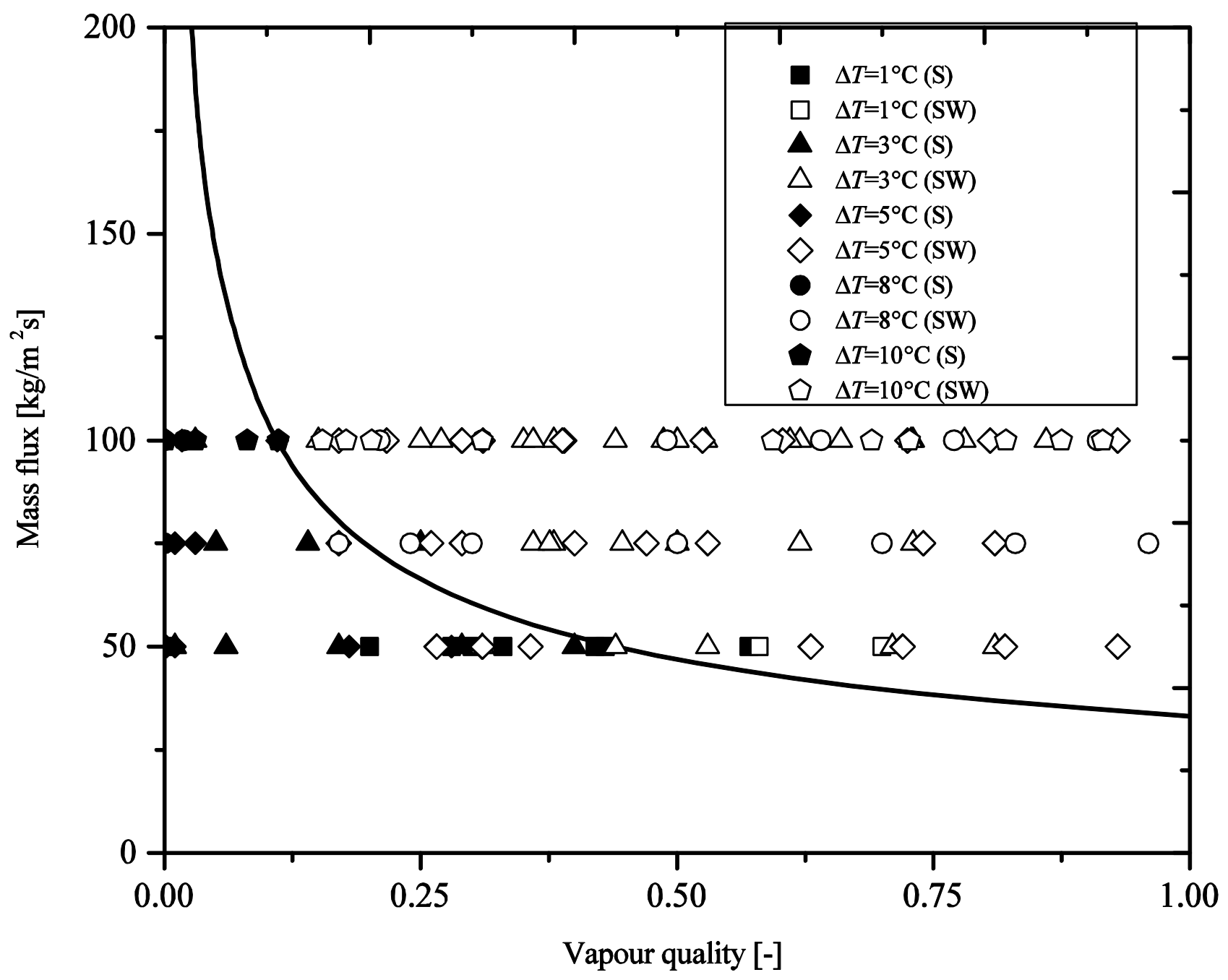

Figure 8. Verification experimental data points generated in this study plotted on the El Hajal et al. [49] map.

However, at a mass flux of $75 \mathrm{~kg} / \mathrm{m}^{2} \mathrm{~s}$, two points were incorrectly predicted. The first was at a temperature difference of $3^{\circ} \mathrm{C}$ and inlet vapour quality of 0.25 . According to the flow pattern map, the flow regime should have been stratified wavy flow; however, stratified flow was observed. Secondly, at a temperature difference of $8^{\circ} \mathrm{C}$ and outlet vapour quality of 0.17 , stratified flow was observed although the flow regime predicted stratified wavy flow.

At a mass flux of $50 \mathrm{~kg} / \mathrm{m}^{2} \mathrm{~s}$, the flow regimes of 4 points were incorrectly predicted in Fig. 8. At a temperature difference of $1^{\circ} \mathrm{C}$ and a quality of 0.58 , the flow regime was observed to be stratified, although the map predicted stratified wavy. At a temperature difference of $5^{\circ} \mathrm{C}$ and qualities of 0.28 , 
0.31 , and 0.4 , the flow regimes were observed to be stratified wavy, although the map predicted that the flow regimes should be stratified flow.

In general, if all three mass fluxes of $100 \mathrm{~kg} / \mathrm{m}^{2} \mathrm{~s}, 75 \mathrm{~kg} / \mathrm{m}^{2} \mathrm{~s}$, and $50 \mathrm{~kg} / \mathrm{m}^{2} \mathrm{~s}$ are considered, the map predicted $85 \%$ of the experimental data points correctly. In general, it seems as if the map inaccurately predicted the flow regimes as the mass flux decreased and the temperature differences increased.

\subsection{Heat transfer coefficients}

The heat transfer coefficients at mass fluxes of $200,150,100,75$, and $50 \mathrm{~kg} / \mathrm{m}^{2} \mathrm{~s}$ at different mean qualities are given in Figs. 9-13 for the different temperature differences. The heat transfer coefficients are the average heat transfer coefficients over the test section lengths and the mean quality values were the average qualities between the inlet and outlet qualities are given in Figs. 5-7.

The results show the expected trend of heat transfer coefficients as a function of vapour qualities that has been shown in previous work. Thus, the heat transfer coefficients increase with increasing values of mean vapour quality and mass flux.

Fig. 9 shows the effect of temperature difference at a mass flux of $200 \mathrm{~kg} / \mathrm{m}^{2} \mathrm{~s}$. The heat transfer coefficients at different temperature differences were all within the uncertainties of the measurements. It was, therefore, concluded that the heat transfer coefficients at a mass flux of $200 \mathrm{~kg} / \mathrm{m}^{2} \mathrm{~s}$ were independent of temperature difference. 


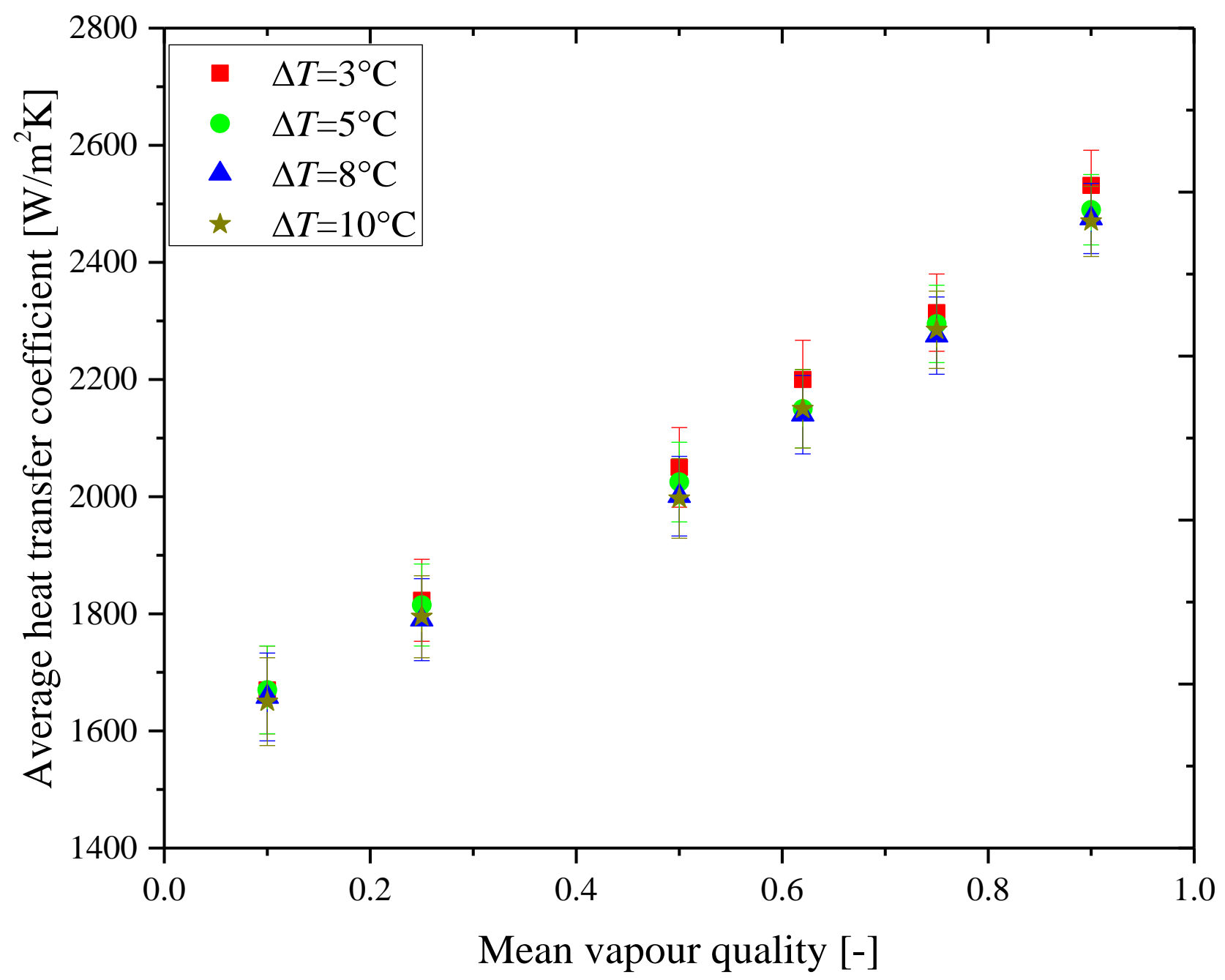

Figure 9. Heat transfer coefficients as function of different wall and refrigerant saturation temperature differences, $\Delta T$, at different mean qualities during condensation at a mass flux of $200 \mathrm{~kg} / \mathrm{m}^{2} \mathrm{~s}$.

At a mass flux of $150 \mathrm{~kg} / \mathrm{m}^{2} \mathrm{~s}$ (Fig. 10), the effect of temperature difference was only detected noticeably at a low vapour quality of 0.1 , which was observed to be stratified flow, while all the other flow regimes were stratified wavy flow. The percentage difference between the measured heat transfer coefficients for the extremes of temperature differences $\left(3\right.$ and $\left.10{ }^{\circ} \mathrm{C}\right)$ at a quality of 0.1 was $12 \%$. However, at vapour qualities greater than 0.25 , the temperature difference had a negligible effect on the value of the heat transfer coefficients. 


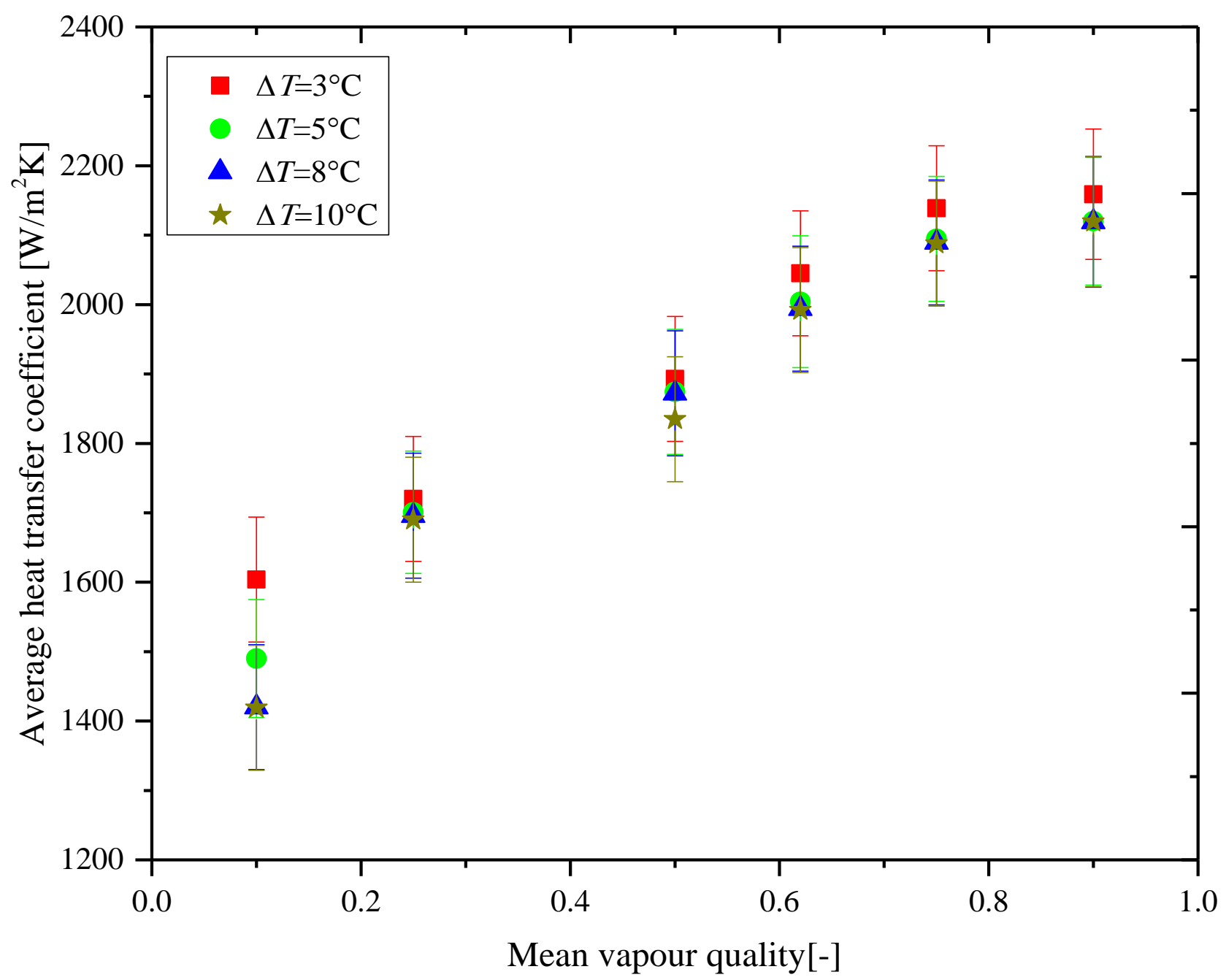

Figure 10. Heat transfer coefficients as function of different wall and refrigerant saturation temperature differences, $\Delta T$, at different mean qualities during condensation at a mass flux of $150 \mathrm{~kg} / \mathrm{m}^{2} \mathrm{~s}$.

Fig. 11 shows the effect of temperature difference at a mass flux of $100 \mathrm{~kg} / \mathrm{m}^{2} \mathrm{~s}$. Except for the one point at a quality of 0.15 which is in the stratified flow regime, all the other experimental conditions were taken in the stratified wavy flow regime. The results show that, in general, the heat transfer coefficients increase as the temperature difference decreases. The effect of the temperature difference is more dominant at higher qualities. For example, if the heat transfer coefficients at temperature differences of 3 and $10{ }^{\circ} \mathrm{C}$ are compared, the increase in the heat transfer coefficient is $10 \%$ at a vapour quality of 0.25 , while at a vapour quality of 0.62 , the increase is $13 \%$. 


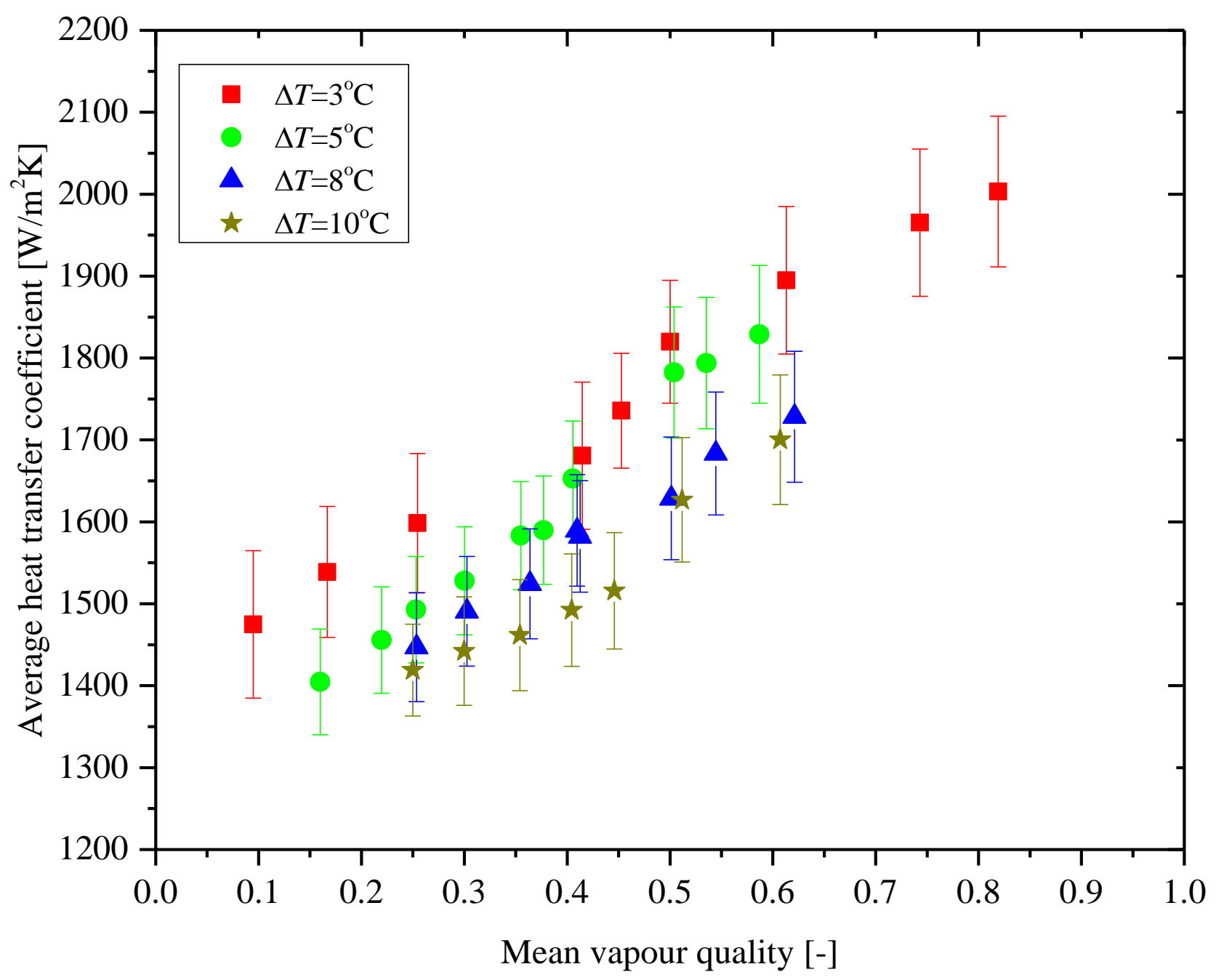

Figure 11. Heat transfer coefficients as function of different wall and refrigerant saturation temperature differences, $\Delta T$, at different mean qualities during condensation at a mass flux of $100 \mathrm{~kg} / \mathrm{m}^{2} \mathrm{~s}$.

At a mass flux of $75 \mathrm{~kg} / \mathrm{m}^{2} \mathrm{~s}$ (Fig. 12), the same conclusion can be made about the effect of temperature difference: the heat transfer coefficients are dependent on temperature difference and increase as the temperature difference decrease. 


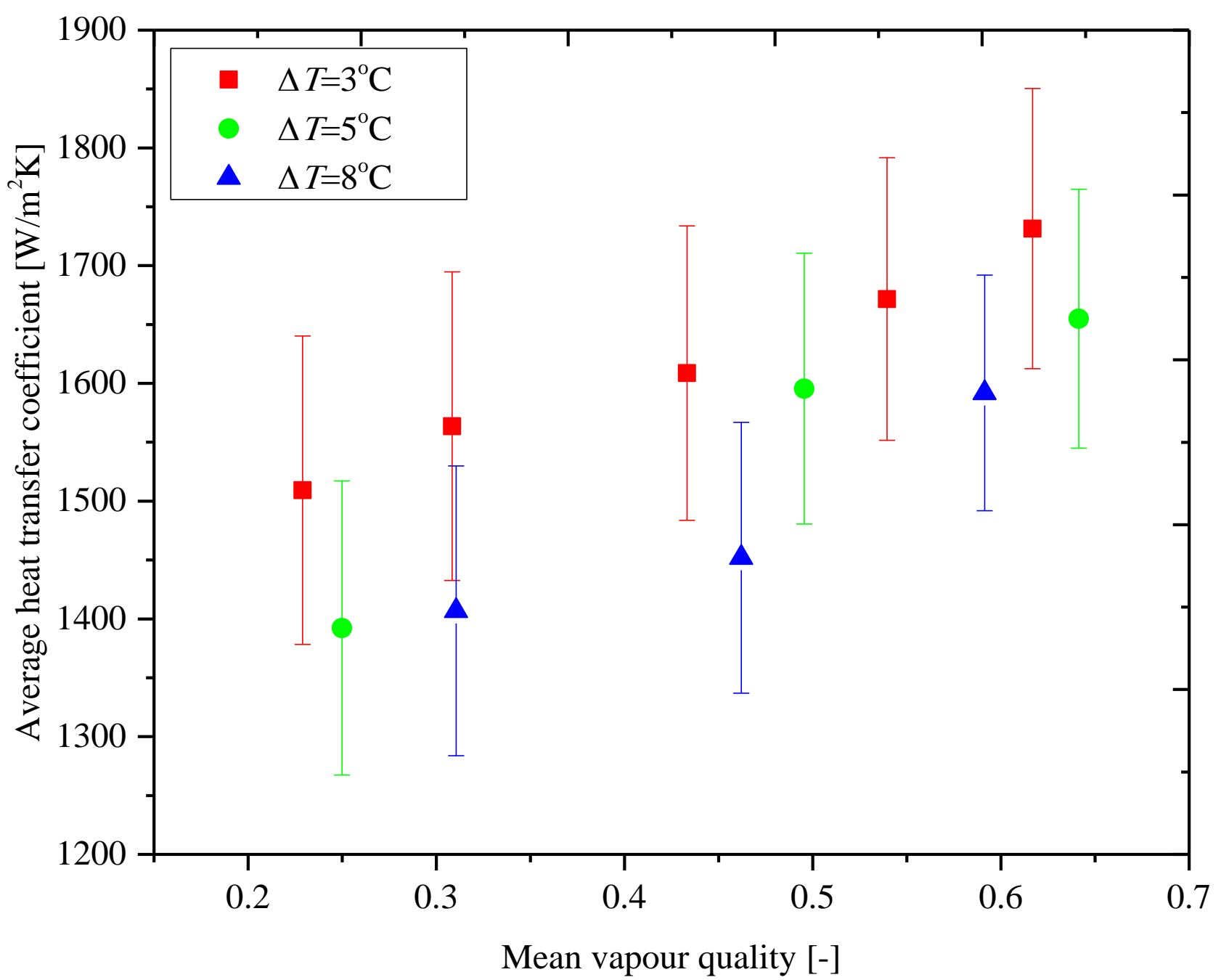

Figure 12. Heat transfer coefficients as functions of different wall and refrigerant temperature differences, $\Delta T$, at different mean qualities during condensation at a mass flux of $75 \mathrm{~kg} / \mathrm{m}^{2} \mathrm{~s}$.

Fig. 13 shows the effect of temperature difference at a mass flux of $50 \mathrm{~kg} / \mathrm{m}^{2} \mathrm{~s}$. Again, the conclusion about temperature difference made for mass fluxes of $150-75 \mathrm{~kg} / \mathrm{m}^{2} \mathrm{~s}$ can be made for the mass flux of $50 \mathrm{~kg} / \mathrm{m}^{2} \mathrm{~s}$. However, the data points were not sufficient enough for any conclusions about the influence of quality to be made. 


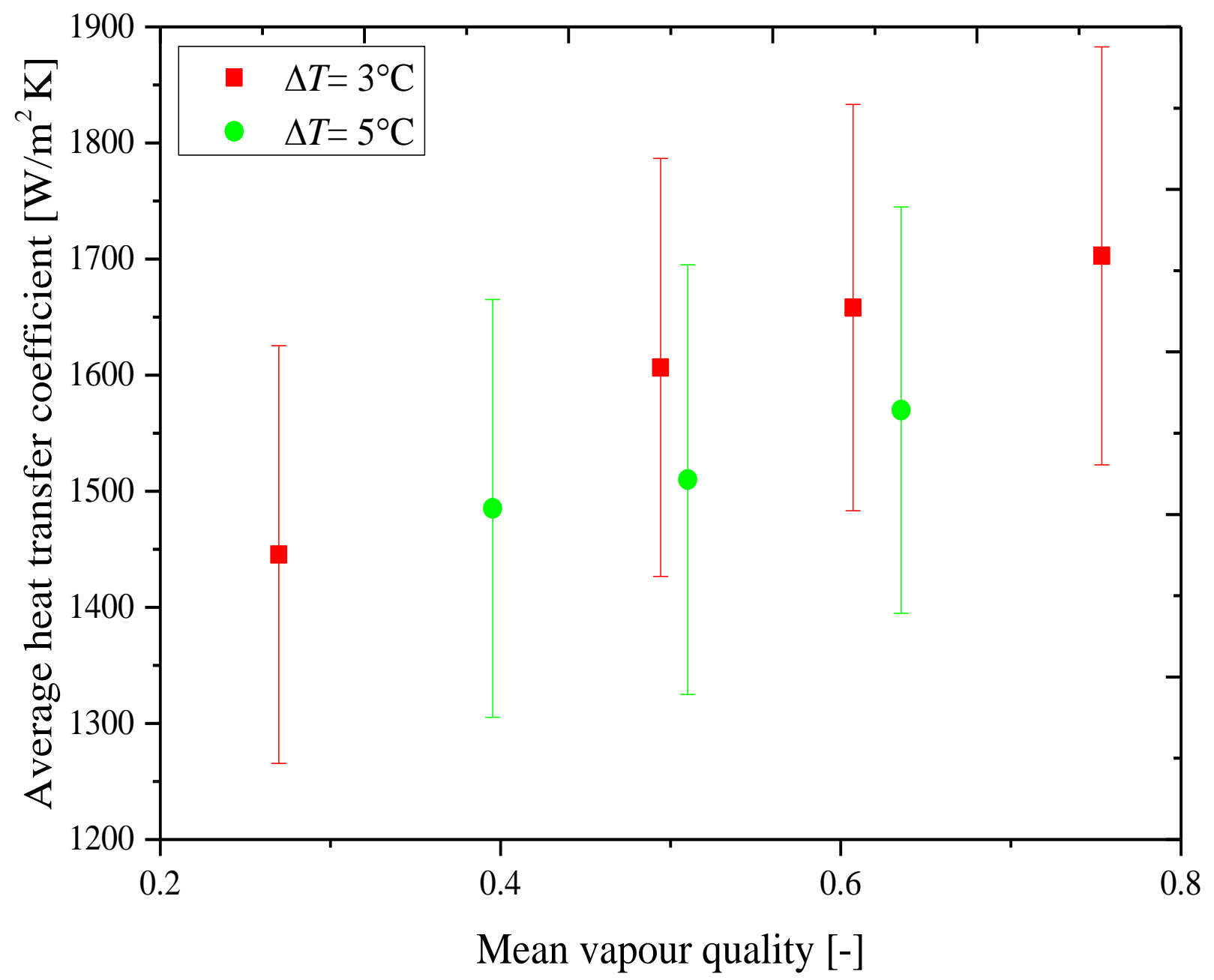

Figure 13. Heat transfer coefficients as functions of different wall and refrigerant temperature differences, $\Delta T$, at different mean qualities during condensation at a mass flux of $50 \mathrm{~kg} / \mathrm{m}^{2} \mathrm{~s}$.

The general conclusions that can be made when comparing Figs. 9-13 were that at mass fluxes of 50$100 \mathrm{~kg} / \mathrm{m}^{2} \mathrm{~s}$, the condensing heat transfer coefficients were temperature dependent. The heat transfer coefficients increased as the temperature differences decreased. The heat transfer coefficients increased as the temperature differences decreased. It can thus be concluded that the effect of $\Delta T$ was more significant at lower mass fluxes due to the existence of gravity-dominated flow like stratified or stratified-wavy flow. In these types of flow patterns the conduction resistance through the liquid film played a more significant role. With an increase in film thickness with $\Delta T$ the thermal resistance of heat transfer increased and resulted in lower heat transfer coefficients. At higher mass fluxes the flow regimes were almost annular and shear stresses played the main role in the total thermal resistance or 
heat transfer coefficients, therefore the increase in film thickness with respect to $\Delta T$ had a negligible effect on the heat transfer coefficients.

Furthermore, at a mass flux of $100 \mathrm{~kg} / \mathrm{m}^{2} \mathrm{~s}$, it was found that the effect of the temperature difference was more dominant at higher qualities. This effect was only observed at this specific mass flow rate.

\section{Comparison with literature}

The results of this study at mass fluxes of 50,75 , and $100 \mathrm{~kg} / \mathrm{m}^{2} \mathrm{~s}$ are compared in Fig. 14 to the theoretical models of Shah [39], Cavallini and Zecchin [69], Akers et al. [70], Cavallini et al. [46], Haraguchi et al. [59], Dobson and Chato [57], and Shah [48]. The comparison was only conducted with the mass fluxes that were found to be temperature dependent.

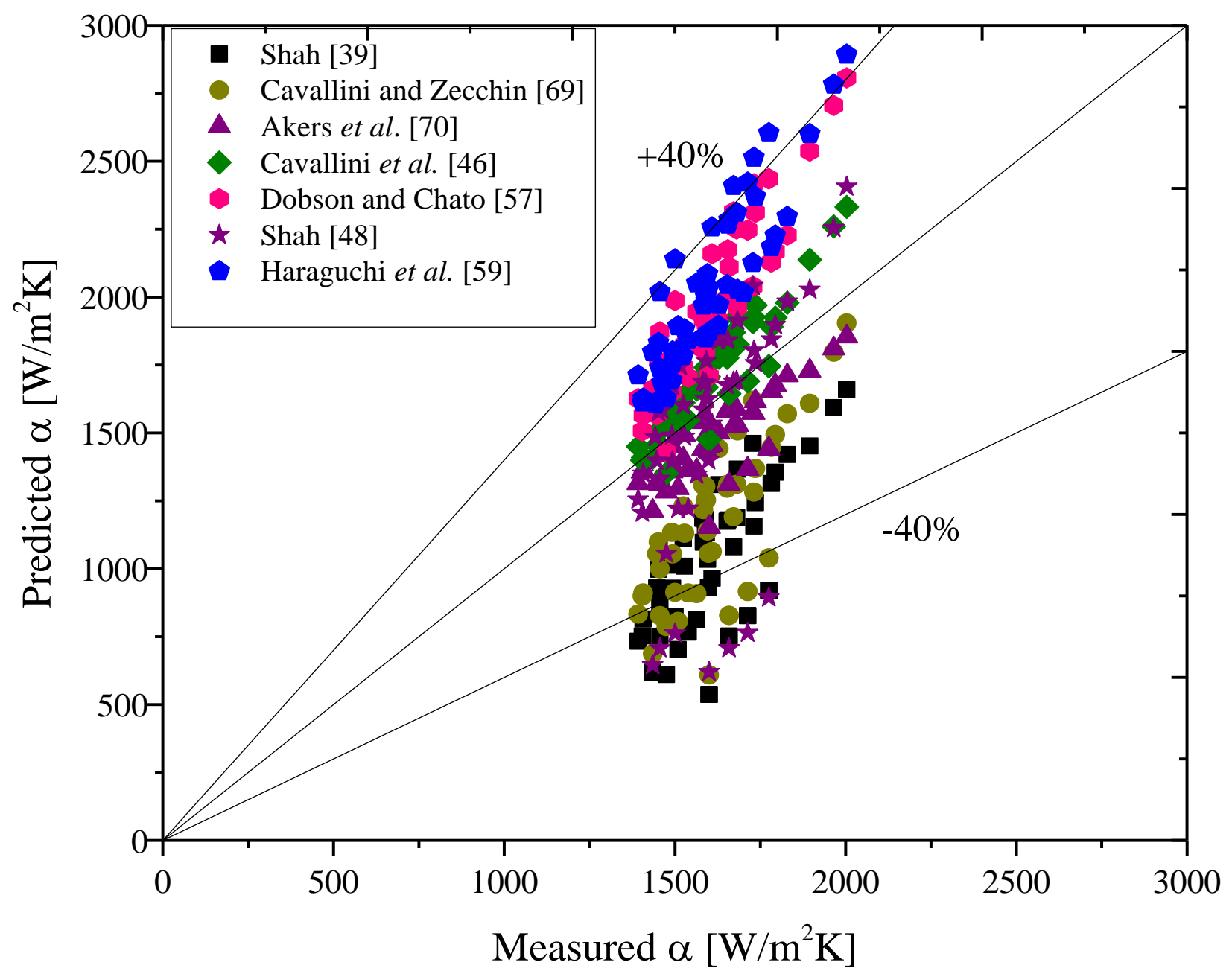

Figure 14. Comparison of experimental data with several theoretical models from literature. 
The comparison shows that the experimental results of this study were lower than the predicted values of Cavallini et al., Haraguchi et al., and Dobson and Chato, but higher than the predicted values of Akers et al. and Cavallini and Zecchin. With respect to the newest model of Shah [48], some of the results of our experiments were higher while others were lower.

The absolute mean deviations in comparison to the theoretical models of Shah, Cavallini and Zecchin, Akers et al, Cavallini et al., Haraguchi et al., Dobson and Chato, and the newest method of Shah correlations were $42 \%, 29 \%, 21 \%, 19 \%, 31 \%, 27 \%$, and $25 \%$, respectively. The maximum deviations per data point were generally recorded at the lowest mass flux of $50 \mathrm{~kg} / \mathrm{m}^{2} \mathrm{~s}$. This showed that the theoretical models became error prone with decreasing mass fluxes. In general, it was also found that as the temperature difference increased, the absolute mean deviation decreased.

With respect to the Cavallini et al. [46] correlation, the experimental results compared well only at vapour qualities below 0.2. It was also found that, for the newest Shah [48] correlation, the experimental data correlated to within $17 \%$ for mass fluxes of 75 and $100 \mathrm{~kg} / \mathrm{m}^{2} \mathrm{~s}$. However, at a mass flux of $50 \mathrm{~kg} / \mathrm{m}^{2} \mathrm{~s}$, the absolute mean deviation was $54 \%$.

Following the instructions of Shah, our data points at this mass flux fell on the "Shah Regime III" (Shah), which represented stratified flows. In that regime, Shah neglected the heat transfer from the condensate in the liquid pool at low mass velocities and this ultimately lowered the heat transfer coefficients. If the "Shah Regime II" equation (representing stratified wavy flow) had been used for all the mass fluxes $\left(50,75\right.$, and $\left.100 \mathrm{~kg} / \mathrm{m}^{2} \mathrm{~s}\right)$ at which experiments in this study were conducted, the absolute mean deviation would have decreased from $17 \%$ to $12 \%$. Although, this modification can be considered for implementation, there is no theoretical justification for the model proposed by Shah [48], as our experimental observations shows that only $65 \%$ of our measurements were conducted in the stratified wavy flow regime. 


\section{Revised theoretical model}

From the previous section, it was deduced that the heat transfer models of Akers et al. [70] and Cavallini et al. [46] predicted the results of our experiments with the lowest absolute mean deviations. The Akers et al. model is a semi-empirical, two-phase multiplier-based correlation which defines the all-liquid mass flow rate. It also provides the same heat transfer coefficient as for an annular condensing flow. The general limitation of this correlation, and others of its type, is that it does not include sufficient variables to accurately describe condensation in tube flow. On the other hand, the Cavallini et al. model is based on the physical description of the actual flow structure, and it predicts and identifies the local two-phase flow pattern based on localised flow conditions. This model also requires a reliable two-phase flow pattern map. We have, therefore, selected the Cavallini et al. correlation [46] for our revised model, which takes into consideration several heat transfer coefficients that contribute to the total heat transfer coefficient. The total heat transfer coefficient is given as

$$
{ }_{D}=\left[\alpha_{A}\left(J_{v}^{T} / J_{v}\right)^{0.8}-{ }_{\text {strat }}\right]\left(J_{v} / J_{v}^{T}\right)+{ }_{\text {strat }}
$$

with $\alpha_{A}$, the annular flow heat transfer coefficient, given as

$$
{ }_{A}={ }_{l o}\left[1+1.128 x^{0.8170}\left(\rho_{l} / \rho_{v}\right)^{0.3685}\left(\mu_{l} / \mu_{v}\right)^{0.2363}\left(1-\mu_{v} / \mu_{l}\right)^{2.144} \operatorname{Pr}_{l}^{-0.1}\right]
$$

and the liquid only heat transfer coefficient, $\quad$ lo , given as

$$
{ }_{l o}=0.023 R e_{l o}^{0.8} \mathrm{Pr}_{l}^{0.4} k_{l} / d
$$

where strat is the fully-stratified flow heat transfer coefficient. In the dimensionless vapour velocity term, $J_{v}^{T}$, a value of $C_{T}=2.6$ was used as prescribed by Cavallini et al., as we have used R134a as condensing fluid. An analysis of the Cavallini et al. equation showed that it has only the fully- 
stratified flow heat transfer coefficient term which is dependent on the temperature difference, $\Delta T$ which drives the heat transfer at low mass fluxes. It then lent credence to the fact that the Cavallini et al. model may not be predicting this parameter accurately as evidenced by the discrepancy noticed during comparison where it over-predicted the measured heat transfer coefficients. This discrepancy was attributed to the varying temperature differences. Having established that the strat component of the total heat transfer component $(\alpha)$, was responsible for the over prediction of the Cavallini et al. correlation by about $20 \%$, a parametric study was done on the strat to quantify the effects and sensitivity of both the exponents of the temperature difference, $\Delta T$ and the vapour quality on its value. It was then found that the exponent of $\Delta T\left(T_{1}\right)$ was more sensitive to a change in the value of $\alpha_{\text {strat }}$ as compared to a large change in the value of the exponent of vapour quality $(x)\left(\mathrm{T}_{2}\right)$ on the liquid only heat transfer coefficient term, $\left(\alpha_{l o}\right)$ component of the $\left(\alpha_{\text {strat }}\right)$. This then led to the modification of the existing correlation as shown in Eq.22

$$
\begin{aligned}
\text { strat }=0.725[ & \left.+0.741[(1-x) / x]^{0.3321}\right]^{-1}\left[k_{l}^{3} \rho_{l}\left(\rho_{l}-\rho_{v}\right) g h_{l v} /\left(\mu_{l} d_{i} \Delta T\right)\right]^{T_{1}} \\
+ & \left(1-x^{T_{2}}\right) \alpha_{l o}
\end{aligned}
$$

In Eq. (22), the exponents $T_{l}$ and $T_{2}$ proposed by Cavallini et al. were 0.25 and 0.087 , respectively. It has been found that, by using the values $T_{1}=0.245$ and $T_{2}=0.25$ for low mass fluxes $\left(G \leq 100 \mathrm{~kg} / \mathrm{m}^{2} . \mathrm{s}\right)$, the mass fluxes can be estimated more accurately, as shown in Fig. 15 . The measured and predicted heat transfer coefficients with the original Cavallini et al. equation for different mass fluxes are shown in Fig. 15a. The figure shows that 53\% of the heat transfer coefficients outside the $\pm 10 \%$ range were for mass fluxes lower than $100 \mathrm{~kg} / \mathrm{m}^{2} \mathrm{~s}$. In Fig. $15 \mathrm{~b}$, the Cavallini et al. equation was used to determine the heat transfer coefficients, but with $T_{l}=0.245$, and $T_{2}=0.25$. These values were only used for mass fluxes lower or equal than $100 \mathrm{~kg} / \mathrm{m}^{2} \mathrm{~s}$, while the original proposed values of 0.25 and 0.087 were used for all the mass fluxes larger than $100 \mathrm{~kg} / \mathrm{m}^{2} \mathrm{~s}$. This adjustment resulted in $90 \%$ of the data at low mass fluxes $\left(G \leq 100 \mathrm{~kg} / \mathrm{m}^{2} . \mathrm{s}\right)$, with errors smaller 
than $\pm 10 \%$. The results show that, for the 48 experimental points at low mass fluxes $\left(G \leq 100 \mathrm{~kg} / \mathrm{m}^{2} . \mathrm{s}\right)$, the average errors improved from 25\% (Fig. 15a) to $5 \%$ (Fig. 15b).

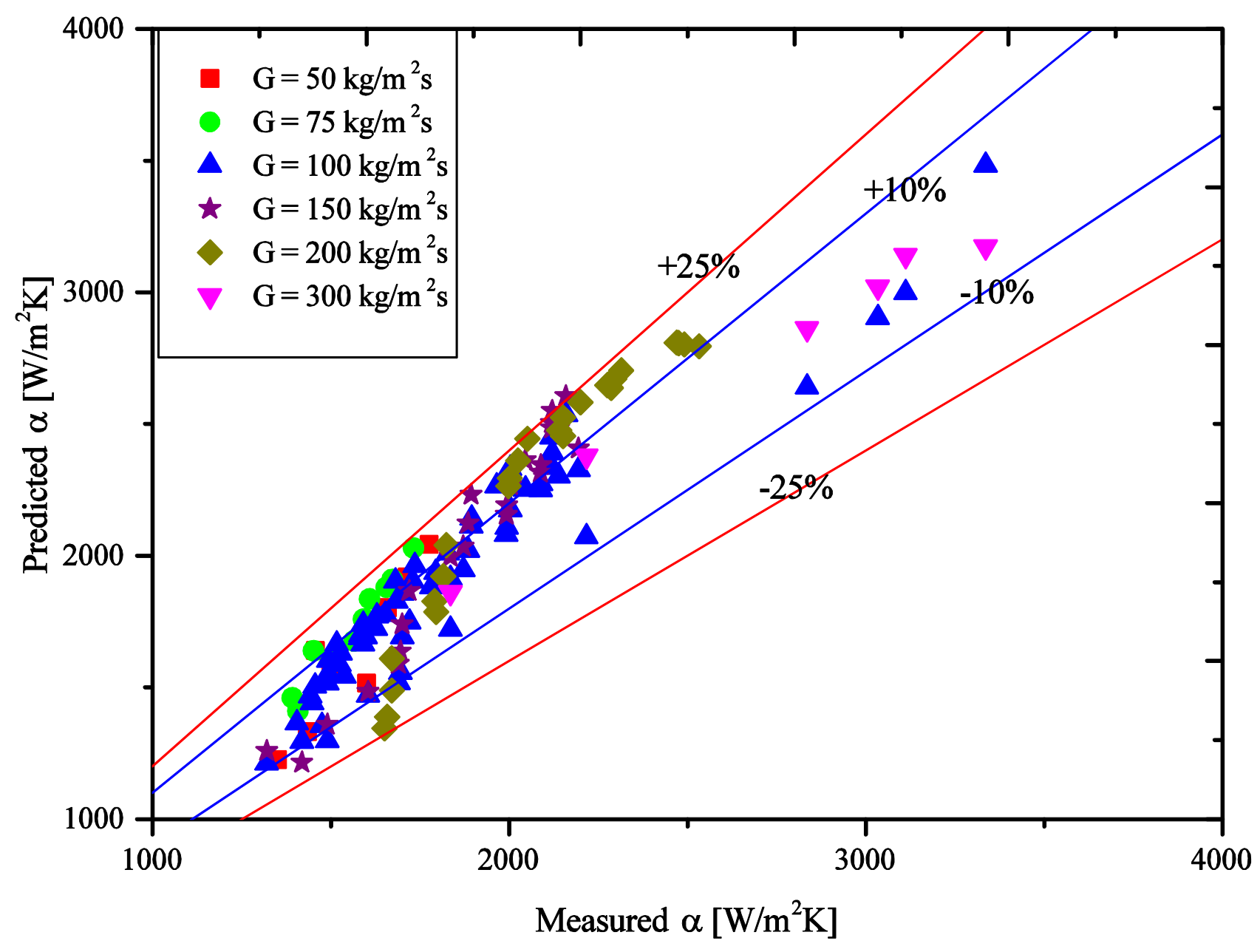

Figure 15a 


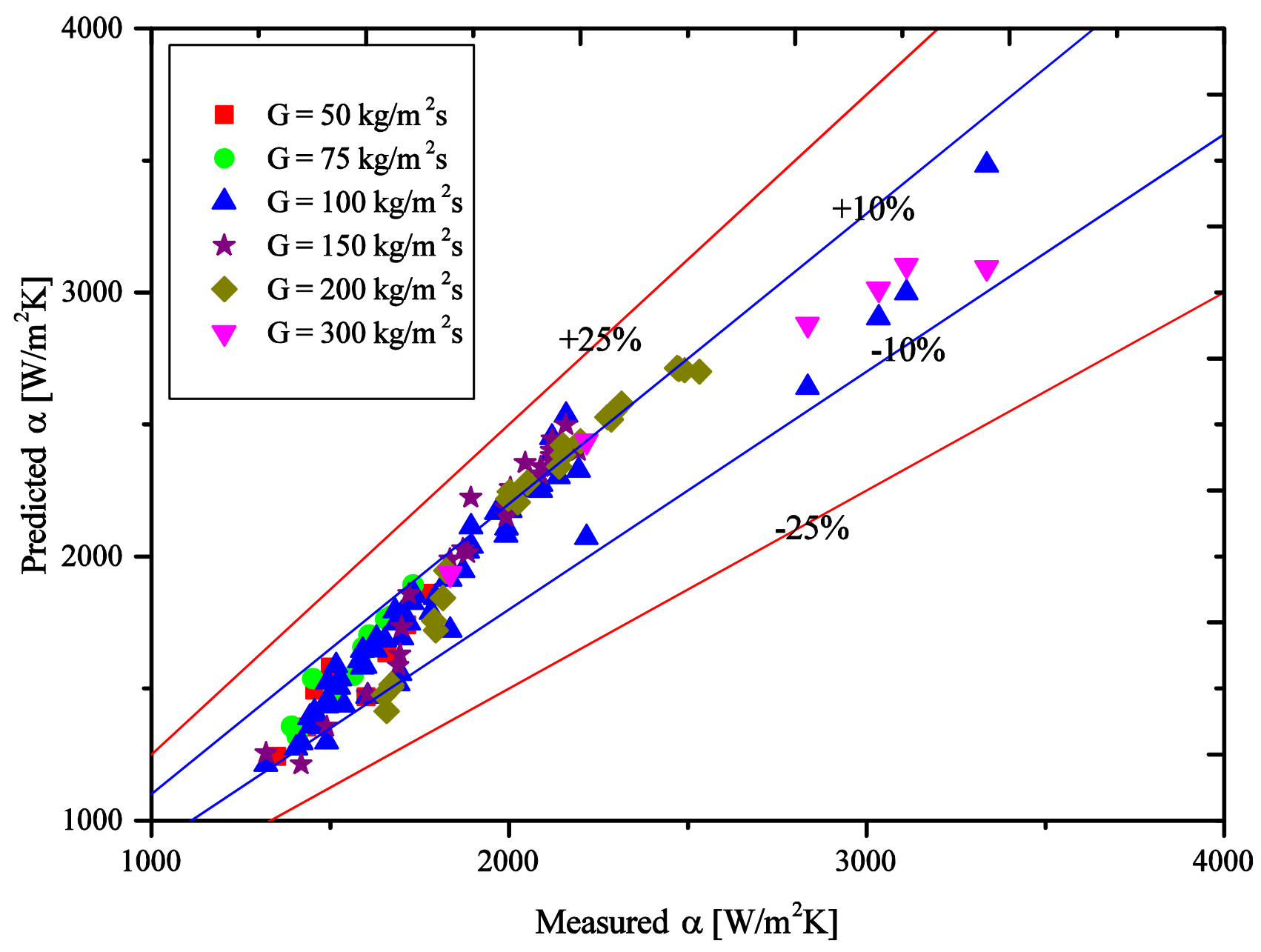

Figure 15b

Figure 15. Measured heat transfer coefficients compared to the Cavallini et al. [48] equation as functions of mass flux. (a) The original values of $T_{1}$ and $T_{2}$, i.e., 0.25 and 0.087 , respectively, were used as proposed by Cavallini et al. [48]; (b) The revised values of $T_{1}$ and $T_{2}$, i.e., 0.245 and 0.25 , respectively, (which take into consideration the temperature differences at low mass fluxes) as suggested in this paper for mass fluxes $G \leq 100 \mathrm{~kg} / \mathrm{m}^{2}$ s were used.

As discontinuities in the $T_{1}$ and $T_{2}$ values as proposed by Cavalanni et al. occurred in this study, we investigated several curve fittings techniques that would produce equations without discontinuities. The equations were of the following format: $T_{1}=f_{1}(G)$ and $T_{2}=f_{2}(G)$; thus, two different functions $\left(f_{1}\right.$ and $\left.f_{2}\right)$ of mass flux, $G$, were obtained. At mass fluxes higher than $100 \mathrm{~kg} / \mathrm{m}^{2} \mathrm{~s}$, the $T_{1}$ and $T_{2}$ values should be 0.5 and 0.087 , respectively. However, at mass fluxes lower than $100 \mathrm{~kg} / \mathrm{m}^{2} \mathrm{~s}$, the $T_{l}$ and $T_{2}$ values should be 0.245 and 0.25 , respectively. The combination of the best and most simple equations were the third order polynomial equations $T_{1}=-1 * 10^{-9} G^{3}+4 * 10^{-7} G^{2}-6 *$ $10^{-6} G+0.2449$ and $T_{2}=-1 * 10^{-8} G^{3}+1 * 10^{-6} G^{2}-0.0012 G+0.2698$. However, both these 
equations show that the first three terms contribute very little to the values of $T_{1}$ and $T_{2}$, and that the last terms of 0.245 and 0.25 contribute the most. Thus, if the third order polynomial equations are used rather than the values of 0.245 and 0.25 , then it will have an insignificant effect on the results in Fig. $15 b$.

The proposed correlation may be used as a universal model because it is a modification of an already existing universal flow pattern based heat transfer model. The experimental and test conditions (besides the low mass fluxes) used in arriving at this modification were similar to many previous studies.

\section{Conclusions}

There have been many experimental and theoretical studies on condensation inside smooth horizontal tubes. However, limited studies have been conducted on the effect of the temperature difference between the wall temperature on which the condensation occurred and the refrigerant saturation temperature on the heat transfer coefficients. It was, therefore, the purpose of this study to investigate the effect of this temperature difference on heat transfer coefficients at low mass fluxes during condensation. This was done with experiments conducted at five different mass fluxes of 50, 75, 100, 150 , and $200 \mathrm{~kg} / \mathrm{m}^{2} \mathrm{~s}$ during the convective condensation of R134a in a smooth horizontal tube with an internal diameter of $8.38 \mathrm{~mm}$. Experiments were conducted with temperature differences from $3{ }^{\circ} \mathrm{C}$ to $10^{\circ} \mathrm{C}$ at a condensing temperature of $40^{\circ} \mathrm{C}$. The inlet and outlet qualities of the condensing refrigerant were determined, and videos of both the inlet and outlet flow regimes were captured.

The observed flow patterns were compared to a flow regime map, and it was found that the map predicted most of the experimental data points correctly. In general, however, the map inaccurately predicted the flow regimes as the mass flux decreased and the temperature differences increased. It was found that the effect of temperature difference on the heat transfer coefficients began to show at a mass flux of $150 \mathrm{~kg} / \mathrm{m}^{2} \mathrm{~s}$, but only at a vapour quality of 0.1 . However, the dependency of heat 
transfer coefficients on temperature difference increased at all vapour qualities when the mass fluxes were lower or equal to $100 \mathrm{~kg} / \mathrm{m}^{2} \mathrm{~s}$. In all cases, for a specific mass flux lower than $100 \mathrm{~kg} / \mathrm{m}^{2} \mathrm{~s}$ and a specific mean quality, the maximum heat transfer coefficients were found at the lowest temperature difference, while the minimum heat transfer coefficients were found at the maximum temperature difference. Finally, as the mass flux decreased, the heat transfer coefficients became more dependent on the temperature difference.

The heat transfer coefficients from this study were also compared to six correlations from literature, and it was found that the literature did not accurately predict the heat transfer coefficients at low mass fluxes. In general, as the temperature difference increased, the errors between measurements and predictions increased. Two minor revisions to one of these correlations were suggested in a term that is influenced by temperature difference. It was found that, when these two revisions to the correlations were introduced, the heat transfer coefficients could be predicted more accurately at low mass fluxes.

\section{Acknowledgments}

We are grateful for the funding received from the NFR, TESP, and University of Pretoria/Stellenbosch University. SANERI/SANEDI, CSIR, EEDSM Hub and NAC. This study would not have been successful without their support.

\section{References}

[1] A. Cavallini, G. Censi, D. Del Col, L. Doretti, G.A. Longo, L. Rossetto, C. Zilio, Condensation inside and outside smooth and enhanced tubes -A review of recent research, International Journal of Refrigeration, 26(4) (2003) 373-392.

[2] A.S. Dalkilic, S. Wongwises, Intensive literature review of condensation inside smooth and enhanced tubes, International Journal of Heat and Mass Transfer, 52(15-16) (2009) 3409-3426. [3] L. Doretti, C. Zilio, S. Mancin, A. Cavallini, Condensation flow patterns inside plain and microfin tubes: A review, International Journal of Refrigeration, 36(2) (2013) 567-587.

[4] B.M. Fronk, S. Garimella, In-tube condensation of zeotropic fluid mixtures, International Journal of Refrigeration, 36(2) (2012) 534-561.

[5] O. García-Valladares, Review of in-tube condensation heat transfer correlations for smooth and microfin tubes, Heat Transfer Engineering, 24(4) (2003) 6-24. 
[6] S. Lips, J.P. Meyer, Two-phase flow in inclined tubes with specific reference to condensation: A review, International Journal of Multiphase Flow, 37(8) (2011) 845-859.

[7] J.R. Thome, Condensation Inside Tubes, Engineering Data Book III, (1979) (2006) 1-27.

[8] R. Enright, N. Miljkovic, J.L. Alvarado, K. Kim, J.W. Rose, Dropwise condensation on micro-and nanostructured surfaces, Nanoscale and Microscale Thermophysical Engineering, 18(3) (2014) 223 250.

[9] B.M. Fronk, S. Garimella, In-tube condensation of zeotropic fluid mixtures: A review, International Journal of Refrigeration, 36(2) (2013) 534-561.

[10] A.P. Kryukov, V.Y. Levashov, N.V. Pavlyukevich, Condensation from a vapor-gas mixture, Journal of Engineering Physics and Thermophysics, 83(4) (2010) 679-687.

[11] H. Louahlia-Gualous, B. Mecheri, Unsteady steam condensation flow patterns inside a miniature tube, Applied Thermal Engineering, 27(8-9) (2007) 1225-1235.

[12] J.M. Martín-Valdepeñas, M.A. Jiménez, F. Martín-Fuertes, J.A.F. Benítez, Comparison of film condensation models in presence of non-condensable gases implemented in a CFD Code, Heat and Mass Transfer/Waerme- und Stoffuebertragung, 41(11) (2005) 961-976.

[13] A. Odaymet, H. Louahlia-Gualous, Experimental study of slug flow for condensation in a single square microchannel, Experimental Thermal and Fluid Science, 38 (2012) 1-13.

[14] J.W. Rose, Enhanced condensation heat transfer, JSME International Journal, Series B: Fluids and Thermal Engineering, 49(3) (2006) 626-635.

[15] B. Shen, E.A. Groll, A critical review of the influence of lubricants on the heat transfer and pressure drop of refrigerants - Part II: Lubricant influence on condensation and pressure drop, HVAC $\& R, 11(4)(2005)$ 511-526.

[16] S. Lips, J.P. Meyer, Stratified flow model for convective condensation in an inclined tube, International Journal of Heat and Fluid Flow, 36 (2012) 83-91.

[17] S. Lips, J.P. Meyer, Experimental study of convective condensation in an inclined smooth tube. Part II: Inclination effect on pressure drops and void fractions, International Journal of Heat and Mass Transfer, (2012) 405-412.

[18] S. Lips, J.P. Meyer, Experimental study of convective condensation in an inclined smooth tube. Part I: Inclination effect on flow pattern and heat transfer coefficient, International Journal of Heat and Mass Transfer, 55(1-3) (2012) 395-404.

[19] S. Lips, J.P. Meyer, Effect of gravity forces on heat transfer and pressure drop during condensation of R134a, Microgravity Science and Technology, 24(3) (2012) 157-164.

[20] J.P. Meyer, J. Dirker, A.O. Adelaja, Condensation heat transfer in smooth inclined tubes for R134a at different saturation temperatures, International Journal of Heat and Mass Transfer, 70 (2014) 515-525.

[21] D. Jung, Y. Cho, K. Park, Flow condensation heat transfer coefficients of R22, R134a, R407C, and R410A inside plain and microfin tubes, International Journal of Refrigeration, 27(1) (2004) 25-32.

[22] M.H. Kim, J.S. Shin, Condensation heat transfer of R22 and R410A in horizontal smooth and microfin tubes, International Journal of Refrigeration, 28(6) (2005) 949-957.

[23] G. Arslan, N. Eskin, Heat transfer characteristics for condensation of R134a in a vertical smooth tube, Experimental Heat Transfer, 28(5) (2014) 430-445.

[24] H.-S. Lee, C.-H. Son, Condensation heat transfer and pressure drop characteristics of R-290, R600a, R-134a and R-22 in horizontal tubes, Heat and Mass Transfer, 46(5) (2010) 571-584.

[25] E. van Rooyen, M. Christians, L. Liebenberg, J.P. Meyer, Probabilistic flow pattern-based heat transfer correlation for condensing intermittent flow of refrigerants in smooth horizontal tubes, International Journal of Heat and Mass Transfer, 53(7-8) (2010) 1446-1460.

[26] A. Dalkilic, S. Wongwises, Two-phase heat transfer coefficients of R134a condensation in vertical downward flow at high mass flux, Heat Transfer - Theoretical Analysis, Experimental Investigations and Industrial Systems, (2011) 15-32. 
[27] A.S. Dalkilic, S. Wongwises, Experimental study on the modeling of condensation heat transfer coefficients in high mass flux region of refrigerant HFC-134a inside the vertical smooth tube in annular flow regime, Heat Transfer Engineering, 32(1) (2011) 33-44.

[28] A.S. Dalkilic, S. Laohalertdecha, S. Wongwises, Experimental investigation of heat transfer coefficient of R134a during condensation in vertical downward flow at high mass flux in a smooth tube, International Communications in Heat and Mass Transfer, 36(10) (2009) 1036-1043.

[29] L. Liebenberg, J.R. Thome, J.P. Meyer, Flow visualization and flow pattern identification with power spectral density distributions of pressure traces during refrigerant condensation in smooth and micro-fin tubes, Journal of Heat Transfer, 127(3) (2005) 209-220.

[30] R. Suliman, L. Liebenberg, J.P. Meyer, Improved flow pattern map for accurate prediction of the heat transfer coefficients during condensation of R-134a in smooth horizontal tubes and within the low-mass flux range, International Journal of Heat and Mass Transfer, 52(25-26) (2009) 5701-5711. [31] J.A. Olivier, L. Liebenberg, J.R. Thome, J.P. Meyer, Heat transfer, pressure drop, and flow pattern recognition during condensation inside smooth, helical micro-fin, and herringbone tubes, International Journal of Refrigeration, 30(4) (2007) 609-623.

[32] A. Cavallini, G. Censi, D.D. Col, L. Doretti, L. Rossetto, G.A. Longo, Heat transfer coefficients of HFC refrigerants during condensation at high temperature inside an enhanced tube, in: 9th International Refrigeration and Air Conditioning Conference, Purdue, USA, 2002, pp. Paper 563. [33] A. Cavallini, D. Del Col, L. Doretti, G.A. Longo, L. Rossetto, Heat transfer and pressure drop during condensation of refrigerants inside horizontal enhanced tubes, International Journal of Refrigeration, 23(1) (2000) 4-25.

[34] A. Cavallini, G. Censi, D. Del Col, L. Doretti, G.A. Longo, L. Rossetto, Experimental investigation on condensation heat transfer and pressure drop of new HFC refrigerants (R134a, R125, R32, R410, R236ea) in a horizontal smooth tube, International Journal of Refrigeration, 24 (2001) 73-87.

[35] L. Liebenberg, J.P. Meyer, A review of flow pattern-based predictive correlations during refrigerant condensation in horizontally smooth and enhanced tubes, Heat Transfer Engineering, 29(1) (2008) 3-19.

[36] L. Liebenberg, J.P. Meyer, Refrigerant condensation flow regimes in enhanced tubes and their effect on heat transfer coefficients and pressure drops, Heat Transfer Engineering, 29(6) (2008) 506520.

[37] C. Aprea, A. Greco, G.P. Vanoli, Condensation heat transfer coefficients for R22 and R407C in gravity driven flow regime within a smooth horizontal tube, International Journal of Refrigeration, 26 (2003) 393-401.

[38] M. Awad, A. Dalkiliç, S. Wongwises, A critical review on condensation heat transfer in microchannels and minichannels, Journal of Nanotechnology in Engineering and Medicine, 5(1) (2014) 010904.

[39] M.M. Shah, A general correlation for heat transfer during film condensation inside pipes, International Journal of Heat and Mass Transfer, 22(4) (1979) 547-556.

[40] M.M. Shah, An improved and extended general correlation for heat transfer during condensation in plain tubes, HVAC \& R, 15(5) (2009) 889-913.

[41] M.M. Shah, A new flow pattern based correlation for heat transfer during condensation in horizontal tubes, in: International Heat Transfer Conference (IHTC), Kyoto Japan, 2014.

[42] M.M. Shah, Prediction of heat transfer during condensation in inclined plain tubes, Applied Thermal Engineering, 94 (2016) 82-89.

[43] A.O. Adelaja, J. Dirker, J.P. Meyer, Convective condensation heat transfer of R134a in tubes at different inclination angles, International Journal of Green Energy, 13(8) (2016) 812-821.

[44] I.Y. Chen, G. Kocamustafaogullari, Condensation heat transfer studies for stratified, cocurrent two-phase flow in horizontal tubes, International Journal of Heat and Mass Transfer, 30(6) (1987) 1133-1148. 
[45] J.R. Thome, J. El Hajal, A. Cavallini, Condensation in horizontal tubes, part 2: New heat transfer model based on flow regimes, International Journal of Heat and Mass Transfer, 46(18) (2003) 33653387.

[46] A. Cavallini, D.D. Col, L. Doretti, M. Matkovic, L. Rossetto, C. Zilio, G. Censi, Condensation in horizontal smooth tubes: A new heat transfer model for heat exchanger design, Heat Transfer Engineering, 27(8) (2006) 31-38.

[47] F. Kreith, K. Timmerhaus, N. Lior, H. Shaw, R.K. Shah, K.J. Bell, E.F. Kreith, B. Raton, C.R.C. Press, A.E. Bergles, 4 . 15 Heat Transfer Enhancement, (2000).

[48] M.M. Shah, Comprehensive correlations for heat transfer during condensation in conventional and mini/micro channels in all orientations, International Journal of Refrigeration, (2016).

[49] J. El Hajal, J.R. Thome, A. Cavallini, Condensation in horizontal tubes, part 1: Two-phase flow pattern map, International Journal of Heat and Mass Transfer, 46(18) (2003) 3349-3363.

[50] A. Cavallini, G. Censi, D.D. Col, L. Doretti, G.A. Longo, L. Rossetto, Experimental investigation on condensation heat transfer and pressure drop of new HFC refrigerants in a horizontal smooth tube, International Journal of Refrigeration, 24 (2001) 73-87.

[51] S. Lips, J.P. Meyer, Effect of gravity forces on heat transfer and pressure drop during condensation, Microgravity Science and Technology, 24(3) (2011) 157-164.

[52] J.R. Thome, Condensation Inside Tubes, in: Wolverine Engineering Data Book III, 2006, pp. 8-1.

[53] J.C. Chato, Laminar condensation inside horizontal and inclined tubes, ASHRAE Journal, 4 (1962) 52-60.

[54] H. Jaster, P.G. Kosky, Condensation heat transfer in a mixed flow regime, International Journal of Heat and Mass Transfer, 19(1) (1976) 95-99.

[55] H.F. Rooson, J.A. Meyers, Point of values of condensing film coefficients inside a horizontal tube, Chemical Engineering Progress Symposium Series, 61 (1965) 190-199.

[56] A. Singh, M.M. Ohadi, S.V. Dessiatoun, Empirical modelling of stratified wavy flow condensation heat transfer in smooth horizontal tubes, ASHRAE Transactions: Symposia, 9 (1996) 596-603.

[57] M.K. Dobson, C.J. C., Condensation in smooth horizontal tubes. , ASME Journal of Heat Transfer, 120 (1998) 193-213.

[58] W.W. Akers, H.F. Rosson, Condensation inside a horizontal tube, Chemical Engineering Progress Symposium Series, 50 (1960) 145-149.

[59] H. Haraguchi, S. Koyama, T. Fujii, Condensation of refrigerants HCF C 22, HFC134a and HCFC 123 in a horizontal smooth tube (2nd report, proposals of empirical expressions for the local heat transfer coefficient), Transactions of the JSME, Part B, 574(69) (1994) 2117-2124.

[60] H. Caniere, C. T'Joen, A. Willockz, M. De Paepe, M. Christians, E. Van Rooyen, L. Liebenberg, J.P. Meyer, Horizontal two-phase flow characterization for small diameter tubes with a capacitance sensor, Measurement Science and Technology, 18 (2007) 2898.

[61] T. Ji, L. Liebenberg, J.P. Meyer, Heat transfer enhancement during condensation in smooth tubes with helical wire inserts, Heat Transfer Engineering, 30(5) (2009) 337-352.

[62] S. Lips, J.P. Meyer, Experimental study of convective condensation in an inclined smooth tube. Part II: inclination effect on pressure drops and void fractions, Int. J. Heat Mass Transf., 55 (2012) 405-412.

[63] J.A. Olivier, L. Liebenberg, J.R. Thome, J.P. Meyer, Heat transfer, pressure drop, and flow pattern recognition during condensation inside smooth, helical micro-fin, and herringbone tubes, International Journal of Refrigeration, 30 (2007) 609-623.

[64] S.P. Olivier, J.P. Meyer, M. De Paepe, K. De Kerpel, The influence of inclination angle on void fraction and heat transfer during condensation inside a smooth tube, International Journal of Multiphase Flow, 80 (2016) 1-14.

[65] E.W. Lemmon, M.L. Huber, M.O. McLinden, NIST standard reference database 23: reference fluid thermodynamic and transport properties (REFPROP), version 9.1, National Institute of Standards and Technology, Standard reference data program, Gaithersburg, (2013). 
[66] ASHRAE, ASHRAE Standard 41.4: Method for measurement of proportion of lubricant in liquid refrigerant, in, American Society for Heating, Refrigeration, and Air-conditioning Engineers, USA, 2006.

[67] P.F. Dunn, Measurement and data analysis for engineering and science, CRC Press, Boca Raton, 2010.

[68] L. Liebenberg, A.E. Bergles, J.P. Meyer, A review of refrigerant condensation in horizontal microfin tubes, in: The 2001 International Mechanical Engineering Congress and Exposition, Orlando, Florida, 5-10 November 2001, AES-Vol. 40, 2000, pp. 155-168.

[69] A. Cavallini, R. Zecchin, A dimensionless correlation for heat transfer in forced convection condensation, in, Tokyo, Japan, 1974, pp. 309-313.

[70] W.W. Akers, H.A. Deans, O.K. Crosser, Condensation heat transfer within horizontal tubes, Chemical Engineering Progress Symposium Series, 55 (1959) 171-176. 